UNIVERSIDADE DE SÃO PAULO

ESCOLA DE ENFERMAGEM

CYNTHIA DE CASTRO MIRANDA

CUIDADORES DE IDOSOS RESTRITOS AO LEITO:

ESTUDO DA QUALIDADE DE VIDA.

São Paulo

2013 
Cynthia de Castro Miranda

\title{
CUIDADORES DE IDOSOS RESTRITOS AO LEITO: ESTUDO DA QUALIDADE DE VIDA
}

\author{
Dissertação apresentada ao \\ Programa de Pós-Graduação em \\ Enfermagem - PPGE. Na Escola de \\ Enfermagem da Universidade de São \\ Paulo para obtenção do título de Mestra \\ em Ciências \\ Área de Concentração: Saúde \\ Coletiva
}

Orientadora: Prof. ${ }^{a}$ Dr$^{\mathrm{a}}$. Suely Itsuko Ciosak

\section{São Paulo}


AUTORIZO A REPRODUÇÃO E DIVULGAÇÃO TOTAL OU PARCIAL DESTE TRABALHO, POR QUALQUER MEIO CONVENCIONAL OU ELETRÔNICO, PARA FINS DE ESTUDO E PESQUISA, DESDE QUE CITADA A FONTE.

Assinatura:

Data:

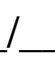

Catalogação na Publicação (CIP)

Biblioteca "Wanda de Aguiar Horta"

Escola de Enfermagem da Universidade de São Paulo

Miranda, Cynthia de Castro

Cuidadores de idosos restritos ao leito: estudo da qualidade de vida / Cynthia de Castro Miranda. - São Paulo, 2013. 96 p.

Dissertação (Mestrado) - Escola de Enfermagem da Universidade de São Paulo.

Orientadora: Prof ${ }^{a}$. Dr ${ }^{\mathrm{a}}$. Suely Itsuko Ciosak

Área de concentração: Saúde coletiva

1. Idosos 2. Cuidadores 3. Assistência a idosos 4.Qualidade de vida 5.Cuidados domiciliares de saúde I Título 
Nome: Cynthia de Castro Miranda

Título: CUIDADORES DE IDOSOS RESTRITOS AO LEITO: ESTUDO DA QUALIDADE DE VIDA.

Dissertação apresentada ao Programa de Pós-Graduação em Gerenciamento em Enfermagem da Escola de Enfermagem da Universidade de São Paulo para obtenção do título de Mestra em Ciências.

Aprovado em:

\section{Banca Examinadora}

Prof. Dr.

Instituição:

Julgamento:

Assinatura:

Prof. Dr. Instituição:

Julgamento: Assinatura:

Prof. Dr. Instituição:

Julgamento: Assinatura: 


\section{DEDICATÓRIA}

Dedico este trabalho a todos que anseiam pela melhoria na saúde coletiva.

E a todos os cuidadores, que tanto admiro, pela coragem diária de enfrentar a pesada carga de cuidar. 


\section{AGRADECIMENTOS}

Primeiramente a Deus, que sempre me deu forças em momentos de angústia, e que sempre me deu mais do que eu mereço.

À Orientadora e Amiga Prof. ${ }^{a}$ Dr $^{\mathrm{a}}$. Suely Itsuko Ciosak, pela sua competência, dedicação e respaldo em todos os momentos que precisei nesta dissertação.

Aos meus pais Carlos Henrique e Alcione, e ao meu irmão Júnior, pelo amor incondicional, amizade, e por estarem juntos comigo em todas as fases da minha vida.

Ao meu noivo e leal companheiro João Carlos Roman Theodoro, pelo amor, carinho e amizade. E à sua família excepcional, que me acolheram.

Às minhas avós, Wanda e Cotinha, que me mostram como a senescência pode ser enriquecedora de conhecimentos. Aos meus avôs, Vizo e Wanderley, que estão ausentes fisicamente, mas estão comigo sempre em pensamento.

Às professoras Dra. Elizabeth Braz, Dra. Márcia Regina Martins Alvarenga e Dra. Maria Amélia pelas valiosas contribuições. E ao professor e Doutor Marcolino pela colaboração em meu trabalho.

À equipe do Projeto SOL da Unimed de Poços de Caldas, pelo carinho e apoio de sempre.

À Escola de Enfermagem da Universidade de São Paulo pela oportunidade desta dissertação. 
“O UNIVERSO DO CUIDAR É MUITO MAIS ABRANGENTE QUE O DE CURAR. PODEMOS NÃO CURAR SEMPRE, MAS SEMPRE PODEMOS CUIDAR E DIMINUIR O SOFRIMENTO". (Camargo e Lopes, em Cuidados Paliativos para a criança com câncer) 


\section{Miranda CC. Cuidadores de Idosos Restritos ao Leito: estudo da qualidade de vida. [Dissertação]. São Paulo: Escola de Enfermagem. Universidade de São Paulo: 2013.}

\section{RESUMO}

A pessoa idosa acometida por alguma doença incapacitante necessita de um cuidador que a ajude a desempenhar tarefas, desde as rotineiras até as mais complexas. O presente estudo teve por objetivo investigar a qualidade de vida (QV) dos cuidadores domiciliares de idosos restritos ao leito, pertencentes ao Projeto de Serviços de Orientação no Lar - SOL da Unimed de Poços de Caldas - MG. Trata-se de um estudo quantitativo, exploratório e descritivo, que utiliza o Questionário World Health Organization Quality of Life - WHOQOL Bref e o Questionário "Perfil dos Cuidadores" como instrumentos de trabalho. Dos 52 idosos acamados, foram entrevistados 44 cuidadores, que atenderam aos critérios de inclusão (ser cuidador principal do idoso por no mínimo seis meses, ser alfabetizado e concordar em participar da pesquisa). Para entender a dinâmica do cuidado, foi importante conhecer as características do idoso acamado. Mais da metade (54,5\%) desses idosos são do sexo feminino, com idade média de 82 anos e peso em média $65,7 \mathrm{~kg}$. As doenças crônicas determinaram a dependência dos idosos, sendo a maioria decorrente de Mal de Alzheimer e Acidente Vascular Encefálico. Quanto aos cuidadores, estes foram divididos em dois grupos: cuidadores informais (CI) e cuidadores formais $(\mathrm{CF})$, a maioria do sexo feminino $(93,2 \%)$. Os cuidadores formais têm o maior contingente na chamada "meia idade". Já os cuidadores informais, metade pertencem à meia idade e a outra metade pertence à chamada $3^{\circ}$ Idade. A maioria desses cuidadores sentem dores no corpo ao realizar as tarefas de cuidar e afirmam não terem tempo para o autocuidado. Apesar de desejarem realizar caminhadas, viagens, ir à missa e passeios, não veem possibilidades, principalmente por não terem com quem rodiziar o cuidado e com isso aumenta a sobrecarga. Quanto às práticas de atividades físicas e alongamentos, essas são pouco adotadas entre os cuidadores. A QV avaliada 
por meio do WHOQOL-Bref apontou-a como "intermediária", não tendo diferença significativa para os dois grupos. O domínio físico teve o melhor escore médio em relação às outras facetas, estando bem próximo à QV "boa". Já o domínio psicológico e o social tiveram o pior escore, sendo classificadas como "intermediária". O escore médio do domínio meio ambiente ficou entre "intermediária". A QV dos cuidadores foi alterada após cuidar do idoso acamado e mostra que descuidam da sua própria saúde. Uma assistência fisioterápica dirigida ao cuidador, com foco no seu condicionamento físico, poderia contribuir para um melhor enfrentamento dessa rotina diária e com isso melhorar a sua QV.

PALAVRAS CHAVE: idoso, cuidador, qualidade de vida e cuidado domiciliar. 


\title{
Miranda CC. Caregivers for Seniors Restricted Bed: quality of life study. (Dissertação). São Paulo: Escola de Enfermagem. Universidade de São Paulo: 2013.
}

\begin{abstract}
The Elder affected by some crippling disease requires a caregiver to help perform tasks, from routine to the most complex. The present study aimed to investigate the quality of life ( QOL) of home caregivers of elderly bedridden belonging to the Draft Guidance Services at Home - SUN Unimed Poços de Caldas - MG . This is a quantitative, exploratory and descriptive, using as instruments of analysis World Health Organization Quality of Life - WHOQOL Bref and Questionnaire "Profile of Caregivers" of the 52 elderly bedridden, were interviewed 44 caregivers who met the inclusion criteria (being the primary caregiver for the elderly for at least six months, literate and agree to participate in the research ). To understand the dynamics of care, it was important to know the characteristics of the elderly bedridden. More than half $(54.5 \%)$ of the elderly are women, the average age was 82 years and weigh on average $65.7 \mathrm{~kg}$. Chronic diseases have determined the dependence of the elderly, mostly due to Alzheimer's disease and Stroke. As for caregivers, patients were divided into two groups, informal caregivers ( CI ) and formal caregivers ( CF ), the majority are female $(93.2 \%)$, formal caregivers have the largest contingent in the " middle age " , informal caregivers already half belong to the middle-aged and the other half belongs to the so called 3rd age . Most of these caregivers feel pain in the body to perform the tasks of caring for the elderly, and refer not have time for self-care. Though wish to perform hiking, traveling, going to Mass and tours, see no possibilities, especially for not having someone self-care and thus increases the overhead. Regarding physical activities and stretching, these are poorly adopted among caregivers. QOL assessed by means of the WHOQOL - Bref showed it as "intermediate", with no differences for the two groups. The physical domain had the best average
\end{abstract}


score in relation to other facets, being right next to QV "good." Already the psychological domain social and had the worst score, classified as "intermediate". Mean score for the environment domain was between "intermediate". QOL of caregivers was changed after caring for the elderly and bedridden show that neglects their own health. Physical therapy assistance directed to the caregiver, focusing on your fitness could contribute to a better face this daily routine and so improve their QOL.

KEYWORDS: elderly, caregiver, quality of life and home care. 


\section{LISTA DE TABELAS, QUADROS E FIGURAS}

Gráfico 1 Distribuição da população por sexo e idade, nos 19 anos de 2950-2100, na América Latina e no Caribe.

Gráfico 2 Estimativa da população de 80 anos ou mais de 20 idade por sexo entre os anos de 1980- 2050 no Brasil.

Gráfico 3 Pirâmide etária de Poços de Caldas, 2010.

Tabela 1 Caracterização dos idosos assistidos pelo Projeto

SOL da Unimed de Poços de Caldas assistidos pela população de cuidadores. Poços de Caldas, 2012.

Tabela 2 Caracterização dos cuidadores de idosos do Projeto SOL da Unimed de Poços de Caldas assistidos pela população de cuidadores. Poços de Caldas, 2012.

Tabela 3 A inserção no cuidar dos idosos do Projeto SOL da

Unimed de Poços de Caldas assistidos pela população de cuidadores. Poços de Caldas, 2012.

Quadro 1 Qualidade de vida dos cuidadores de idosos do 59 projeto SOL da Unimed de Poços de Caldas, 2012.

Gráfico 4 Avaliação dos domínios: ambiental, social, 61 psicológico e físico dos cuidadores informais.

Gráfico 5 Avaliação dos domínios: ambiental, social, 61 psicológico e físico dos cuidadores formais.

Quadro 2 Qualidade de vida no aspecto ambiental dos 62 cuidadores de idosos do Projeto SOL da Unimed de Poços de Caldas, 2012.

Quadro 3 Análise da qualidade de vida no aspecto social dos 64 cuidadores de idosos do Projeto SOL da Unimed de Poços de Caldas, 2012.

Quadro 4 Qualidade de vida no aspecto psicológico dos 67 cuidadores de idosos do Projeto SOL da Unimed Poços de Caldas, 2012. 
Quadro 5 Qualidade de vida no aspecto físico dos cuidadores

de idosos do Projeto SOL da Unimed de Poços de caldas, 2012. 


\section{LISTA DE ABREVIATURAS}

$\begin{array}{ll}\text { AVD’s } & \text { Atividades de vida diária } \\ \text { WHOQOL } & \text { World Health Organization Quality Of Life } \\ \text { QV } & \text { Qualidade de Vida } \\ \text { SOL } & \text { Serviços de Orientação no Lar } \\ \text { TCLE } & \text { Termo de consentimento livre e esclarecido } \\ \text { DA } & \text { Doença de Alzheimer } \\ \text { AVE } & \text { Acidente Vascular Encefálico } \\ \text { AMADA } & \text { Associação Maior Apoio ao Doente de Alzheimer } \\ \text { LDL } & \text { Low Density Lipoproteins } \\ \text { HDL } & \text { High Density Lipoproteins } \\ \text { BIREME } & \text { Biblioteca Regional de Medicina } \\ \text { IBGE } & \text { Instituto Brasileiro de Geografia e Estatística } \\ \text { OMS } & \text { Organização Mundial da Saúde } \\ \text { USP } & \text { Universidade de São Paulo } \\ \text { CEP } & \text { Comitê de ética e de Pesquisa } \\ \text { ONU } & \text { Organização das Nações Unidas } \\ \text { CELADE } & \text { Centro Latino Americana e Caribe de Demografia } \\ \text { CI } & \text { Cuidadores Informais } \\ \text { CF } & \text { Cuidadores Formais }\end{array}$




\section{SUMÁRIO}

$\begin{array}{lll}1 . & 17\end{array}$

$\begin{array}{lll}1.1 & \text { ENVELHECIMENTO POPULACIONAL } & 17\end{array}$

1.2 O CUIDADO, O IDOSO E A FAMÍLIA 21

$\begin{array}{lll}1.3 & \text { QUALIDADE DE VIDA }\end{array}$

1.4 A FISIOTERAPIA E A QUALIDADE DE VIDA DO CUIDADOR 28

$\begin{array}{lll}2 . & 31\end{array}$

$\begin{array}{lll}2.1 & \text { OBJETIVO GERAL } & 31\end{array}$

$\begin{array}{lll}2.2 & \text { OBJETIVOS ESPECÍFICOS } & 31\end{array}$

3. METODOLOGIA 32

$\begin{array}{lll}3.1 & \text { TIPO DO ESTUDO }\end{array}$

$3.2 \quad$ LOCAL DO ESTUDO 32

$\begin{array}{lll}3.3 & \text { POPULAÇÃO DO ESTUDO }\end{array}$

3.3.1 Critérios de inclusão 36

\begin{tabular}{l|l}
3.4 & 36
\end{tabular}

$\begin{array}{lll}3.5 & \text { VARIÁVEIS DO ESTUDO } & 37\end{array}$

3.5.1 As variáveis independentes sócio-demográficas e 37

econômicas consideradas neste estudo foram

3.5.2 As variáveis dependentes deste estudo foram 38

$3.6 \quad$ COLETA DE DADOS 38

3.7 PROCEDIMENTOS ÉTICOS PARA A REALIZAÇÃO DA 39 PESQUISA

$\begin{array}{lll}3.8 & \text { ANÁLISE DOS DADOS } & 39\end{array}$

4. RESULTADOS E DISCUSSÃO 41

4.1 CARACTERIZAÇÃO DA POPULAÇÃO ESTUDADA 41

4.1.1 Idosos assistidos pela população de cuidadores $\quad 41$ 
4.1.2 Caracterização dos cuidadores dos idosos dependentes $\quad 45$

4.1.2.1 Cuidadores informais (Cl) 45

4.1.2.2 Cuidadores formais (CF) 46

4.1.2.3 Análise dos dois grupos $-\mathrm{Cl}$ e CF 46

4.2 CONDIÇÕES FÍSICAS E QUALIDADE DE VIDA DOS 58

CUIDADORES DE IDOSOS

4.2.1 Qualidade de vida por Domínios 60

$\begin{array}{lll}\text { 5. CONCLUSÃO } & 73\end{array}$

6. CONSIDERAÇÕES FINAIS 76

$\begin{array}{lll}7 . & \text { REFERÊNCIAS }\end{array}$

APÊNDICE I- PERFIL DOS CUIDADORES

APÊNDICE II - TERMO DE CONSENTIMENTO LIVRE E $\quad 88$

ESCLARECIDO

APÊNDICE III - SOLICITAÇÃO DE AUTORIZAÇÃO 89

INSTITUCIONAL

ANEXO I - WORLD HEALTH ORGANIZATION OF LIFE 90

(WHOQOL - BREF): VERSÃO BRASILEIRA

ANEXO II - DOMÍNIOS E FACETAS DO WHOQOL - BREF 94

ANEXO III - CÁLCULO DOS DOMÍNIOS PADRONIZADOS DO 95

WHOQOL- BREF

ANEXO IV - APROVAÇÃO DO COMITÊ DE ÉTICA 


\section{INTRODUÇÃO}

\subsection{ENVELHECIMENTO POPULACIONAL}

O envelhecimento populacional é o resultado do processo conhecido por "transição demográfica" em que as diferentes sociedades humanas estão deixando de serem sociedades em que predominam as populações jovens e maduras, para se transformarem em sociedades cada vez mais envelhecidas. Esta condição é resultante da queda progressiva das taxas de nascimento e mortalidade, verificadas inicialmente nos países desenvolvidos e, posteriormente, nos países em desenvolvimento. (Fernandes, Gonçalves, Costa, 2002).

A Constituição da República Federativa do Brasil de 1988, ao tratar do assunto do envelhecimento, denominou que o idoso é qualquer indivíduo que pertença à faixa etária igual ou superior a 60 anos, sendo esta confirmada na Política Nacional do Idoso, sancionada pelo Congresso pela Lei $\mathrm{n}^{\circ}$ 8.842, de 02 de Janeiro de 1994, objetivando assegurar os direitos sociais e criando condições de autonomia, integração e participação efetiva dos idosos na sociedade, por meio dos Conselhos Nacionais, Estaduais, do Distrito Federal e Municipais do Idoso, sem entanto classificá-los em subgrupos etários. (Braz, Seganfredo, Ciosak, 2006).

Nos países desenvolvidos a transição demográfica ocorreu no período da Revolução Industrial. Com o surgimento das pílulas contraceptivas, ocorreu uma redução nas taxas de fecundidade e graças às melhores condições sociais e de saneamento básico, além do uso de antibióticos e vacinas, a expectativa de vida aumentou. (Ramos, Veras, Kalachi 1987).

Já nos países em desenvolvimento, em especial no Brasil, a transição demográfica ocorreu em outro momento histórico. Entre os anos 1940 e 1960, o Brasil teve um declínio significativo da mortalidade e alto nível da natalidade, o que gerou uma população mais jovem. Entretanto, a partir da década de 1960, houve a diminuição significativa da taxa de fecundidade, em especial da população com alto poder aquisitivo, e em regiões mais 
desenvolvidas, como Sul e Sudeste. (Nasri, 2008).

Entre 1960 e 1980, observou-se no Brasil uma queda de 33\% na fecundidade. A diminuição no ritmo de nascimento resulta, em médio prazo, no incremento proporcional da população idosa. Nesse período de 20 anos, a expectativa de vida aumentou em oito anos. Neste século, a população de idosos ultrapassa os 15 milhões de brasileiros (para uma população total de cerca de 170 milhões de habitantes), e em 20 anos chegará a 32 milhões. (Veras, 2003).

De acordo com as previsões da Organização das Noções Unidas (ONU), com a alta natalidade do passado e a diminuição da taxa de mortalidade, a população triplicou na América Latina e no Caribe, entre 1950 a 2010, passando de 167 milhões de habitantes para 589 milhões. Há a probabilidade de no ano de 2100 haver uma população de 657 milhões de habitantes, como mostra o Gráfico 1 (Naciones Unidas, 2013).

Ainda sobre o Gráfico 1, pode-se observar no ano de 2050 o início da inversão da pirâmide demográfica, na qual a base fica mais estreita, ou seja, há menos crianças de 1 a 9 anos do que idosos jovens de 60 a 65 anos. 
Gráfico 1- Distribuição da população por sexo e idade, nos anos de 2950-2100, na América Latina e no Caribe.
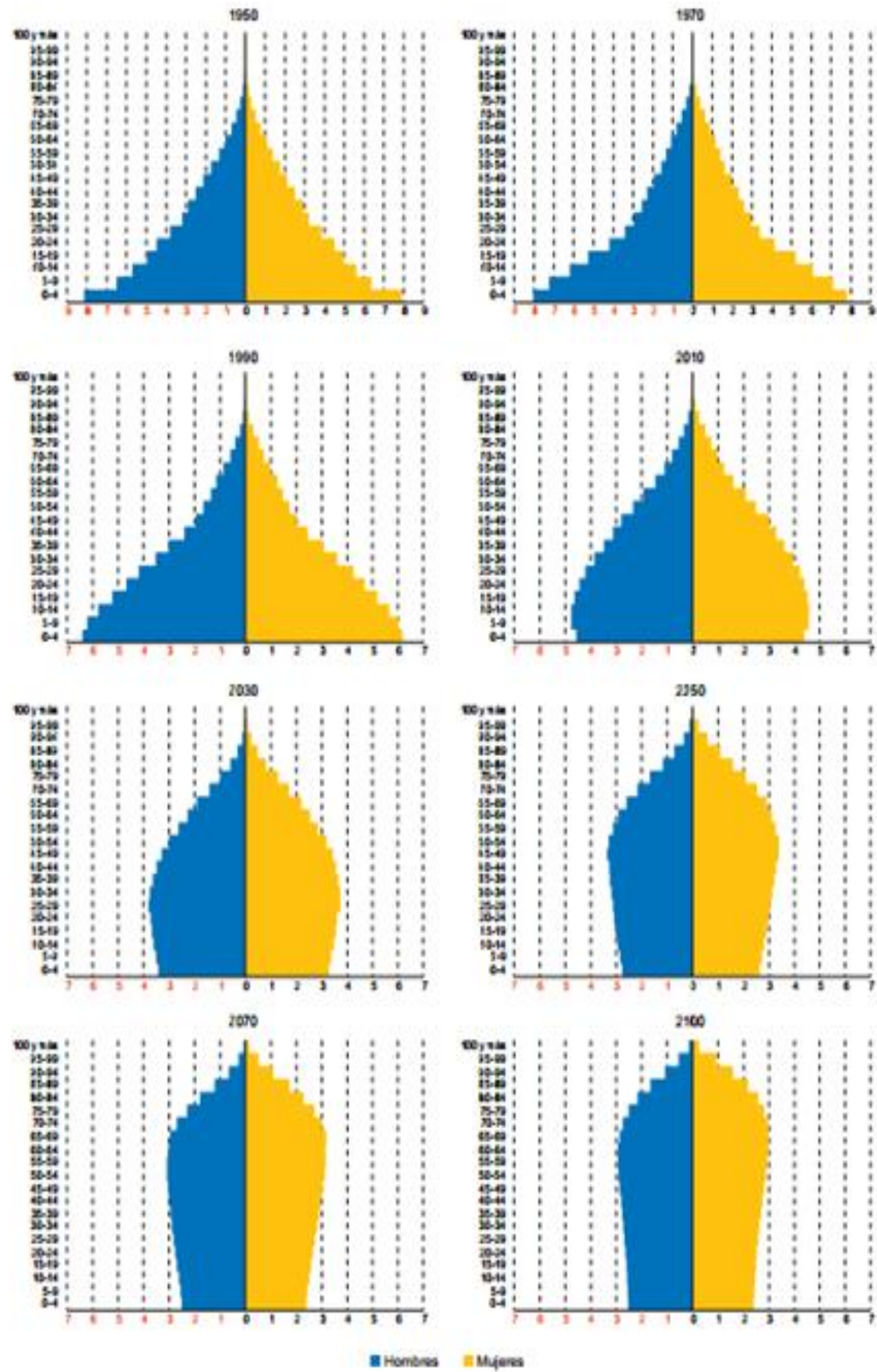

Fonte: Centro Latino Americana e Caribe de demografia (CELADE - Naciones Unidas)

O conceito de Transição Epidemiológica cunhado por Omran (1971) se refere à modificação dos padrões de morbidade, invalidez e morte, que caracterizam uma população e ocorrem em conjunto com outras 
transformações demográficas e sociais. (Chaimowicz, 1997).

O processo engloba três mudanças básicas: a substituição, entre as primeiras causas de morte, das doenças transmissíveis por doenças não transmissíveis e causas externas; o deslocamento da maior carga de morbimortalidade dos mais jovens para os mais idosos; e a transformação de uma situação em que predomina a mortalidade para outra em que a morbidade é dominante. (Chaimowicz, 1997).

O Gráfico 2 do Instituto Brasileiro de Geografia e Estatística (IBGE) ilustra o número cada vez mais crescente de idosos com mais de 80 anos, em ambos os sexos. Em estimativa do número de idosos para o ano de 2050, teremos 7.000.000 idosos do sexo masculino e 9.000.000 idosos do sexo feminino.

Gráfico 2. Estimativa da população de 80 anos ou mais de idade por sexo entre os anos de 1980- 2050 no Brasil.

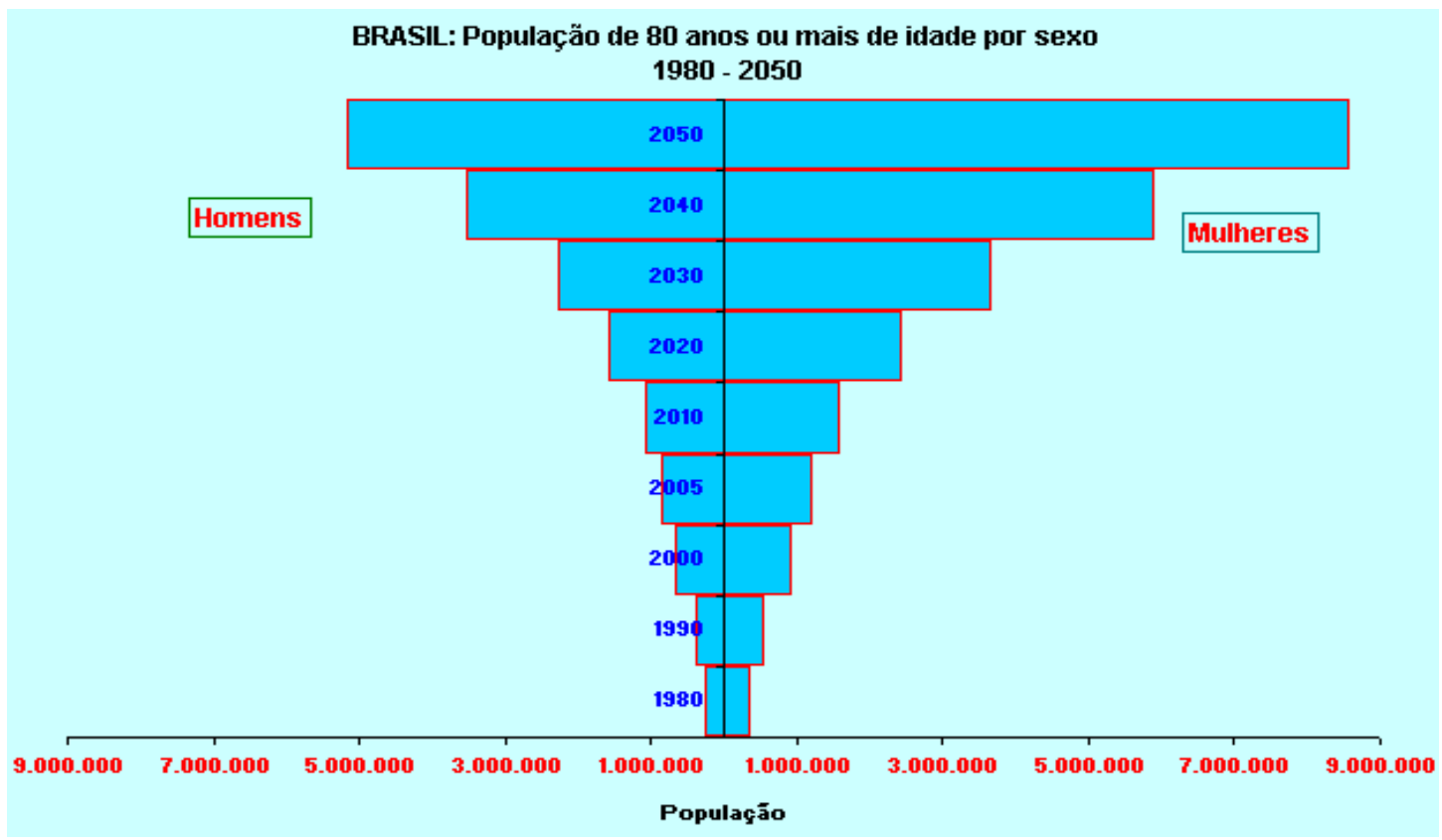

Fonte: www.ibge.gov.br

A quantidade de deficiência pode conduzir uma morbidade que é comprimida dentro de um espaço menor entre o envelhecimento até o acometimento da deficiência e da ocorrência física da morte. $\mathrm{O}$ adiamento das doenças crônicas, por conseguinte, resulta em uma retangularização, não somente na curva da mortalidade, mas também da morbidade. O aumento 
das doenças crônicas levam ao aumento dos custos dos incrementos médicos (Fries, 1980).

Em virtude desse crescimento etário, Castro e Figueiredo (2009) acreditam ser relevante ampliar as pesquisas científicas na área gerontológica, a fim de preparar melhor os profissionais de saúde envolvidos na assistência multidisciplinar ao idoso.

$\mathrm{O}$ envelhecimento populacional brasileiro tem implicado em alterações no perfil epidemiológico e está sendo um dos maiores desafios na saúde pública. (Ferreira, Alexandre, Lemos, 2011). Assim, com o aumento da longevidade, o grande desafio é conseguir uma sobrevida cada vez melhor e que os anos vividos a mais sejam plenos de significado, levando a uma vida digna e respeitosa em que valha a pena ser vivida.

\subsection{O CUIDADO, O IDOSO E A FAMÍLIA}

As atuais mudanças na estrutura etária da população têm como consequência o aumento de enfermidades crônicas e incapacitantes, que ocorrem com maior frequência no processo de envelhecimento, culminando um percentual significativo de pessoas necessitadas de cuidado. (Laham, Silva, 2006).

A presença ou instalação de processos patológicos em idosos provocam alterações em seu quadro funcional, conduzindo-os à situações nas quais deixam de ser totalmente independentes, e passam à condição de dependência, seja ela parcial ou total, temporária ou definitiva. (Ciosak, Braz, 2013)

Os idosos normalmente convalescem de doenças crônicas, algumas com alto grau de dependência, e necessitam de alguém para auxiliar ou fazer suas atividades de vida diária básicas (AVD`s), tornando-se uma questão de saúde pública. (Laham, Silva, 2006).

A pessoa idosa acometida por alguma doença crônica e incapacitante necessita de alguém que a ajude a desempenhar tarefas, desde as rotineiras até atividades mais complexas, como aquelas que dizem respeito ao seu tratamento de saúde. Cuidar para propiciar a recuperação total do paciente, a 
melhoria e estabilização do quadro clínico ou ainda visar somente à manutenção da condição de saúde/doença ou para garantia de uma morte digna fazem parte da mesma modalidade de ação, da mesma função: ser cuidador. (Laham, Silva, 2006).

\footnotetext{
"O que se opõe ao descuido e ao descaso é o cuidado. Cuidar é mais que um ato: é uma atitude. Portanto, abrange mais que um momento de atenção, de zelo e de desvelo. Representa uma atitude de ocupação, preocupação, responsabilização e envolvimento afetivo com o outro" (Boff, 1999).
}

Em sua forma mais antiga, cura em latim se escrevia coera e era usada num contexto de relações de amor e de amizade. (Boff, 1999).

\begin{abstract}
"O cuidado sempre acompanha o ser humano porque este nunca deixará de amar e de se desvelar por alguém, nem deixará de se preocupar e de se inquietar pela pessoa amada. É com o coração (sentimento) que se vê corretamente; o essencial é invisível aos olhos. É o sentimento que torna pessoas, coisas e situações importantes para nós. Esse sentimento profundo se chama cuidado. Que o cuidado aflora em todos os âmbitos, que penetre na atmosfera humana e que prevaleça em todas as relações" (Boff, 1999).
\end{abstract}

Duarte e Diogo (2000) definem que o cuidado humano ou o cuidar de si representa a essência do viver humano. Deste modo, o cuidar do outro sempre representa uma condição temporária e circunstancial, na medida em que o outro se encontra impossibilitado de autocuidar-se.

O autocuidado é de suma importância para qualquer indivíduo, pois é por meio dele que se mantém o corpo saudável e garante sua existência. Sendo assim, pode-se afirmar que o principal cuidador de cada indivíduo é o próprio indivíduo. No entanto, existirão situações em que o individuo não conseguirá exercer o autocuidado, consequentemente resultará na perda de independência. (Almeida, 2005).

Cuidar de um idoso não é uma tarefa simples, mas se o cuidador tiver orientações de como deve cuidar do paciente, for acompanhado por uma equipe multidisciplinar e ter tempo para o autocuidado, o cuidar pode se tornar uma tarefa menos desgastante e até prazerosa.

Desempenhar a tarefa de cuidar de um idoso dependente no domicílio leva à alterações no modo de viver dos cuidadores familiares e 
deflagra diferentes sentimentos vivenciados diariamente.

Quanto maior o grau de dependência e a gravidade da doença do idoso, maior será o grau de estresse gerado na família.

Uma das funções da família é cuidar - cuidado que a princípio os pais têm com os filhos pequenos e, posteriormente, os filhos adultos têm com os pais idosos. É importante, portanto, que todos sejam preparados para serem futuros cuidadores. (Ceschini, 2005).

O conceito de família (do latim famulus, que significa "servo" ou "escravo doméstico". Termo criado na Antiga Roma para designar um novo grupo social, no qual o chefe tinha sob seu poder a mulher, os filhos e os escravos) tem se modificado de acordo com as transformações dos modos de produção social, havendo variâncias culturais dentro do mesmo modo de produção, na mesma época histórica, subjacentes às interferências dadas pelas diferentes culturas que compõem a formação social considerada. (Egry, Fonseca, 2000).

O cuidado com os idosos e com as pessoas dependentes não é algo novo. Deu-se tradicionalmente no âmbito privado do domicílio. A família era conhecida como fonte de cuidados de longa duração para essas pessoas e a figura feminina, a principal, como agente desse cuidado (Rodrigues, Watanabe e Derntl, 2006).

O modelo antigo de família, composto de pai, mãe, muitos filhos, avós e parentes tinha a função precípua de cuidar dos doentes, das crianças e dos idosos (Mazza, 2008).

A modernidade trouxe consigo novos avanços tecnológicos e com isto foram aumentadas as possibilidades de acesso aos meios de cultura e novas oportunidades para todos os membros da família (Mazza, 2008).

Com a entrada da mulher no mercado de trabalho, a diminuição da fecundidade, a migração da população para os centros urbanos, o surgimento de novos papéis de gênero e a maior longevidade de seus membros o novo modelo de família foi criado (Mazza, 2008).

O modelo da família brasileira é hegemônico e visto como ideal a ser seguido pela maioria das pessoas, mas esse modelo tem sofrido fissuras e outros arranjos familiares têm surgido, com o aumento do número de 
famílias matrifocais (Cano e Ferriani, 2000).

Quando um idoso fica dependente de cuidados no domicílio, o cotidiano da família é totalmente alterado em função das atividades colocadas pelo doente. É introduzida uma nova rotina, em função da qual a dinâmica familiar é alterada, desestabilizando relações de intimidade no grupo familiar (Mendes, 2005), mesmo que o cuidador principal seja um cuidador formal e remunerado.

A necessidade de redefinição de papéis entre os membros da família, a "escalação" de alguém para assumir a responsabilidade dos cuidados e, em muitas vezes, a adequação do ambiente, visando atender às demandas do familiar doente que retorna ao lar, podem causar um impacto econômico e social que altera a estrutura familiar. (Perlini, Faro, 2005).

Boillat et al. (1997) apud Laham (2003) escrevem sobre a importância de se observar com mais atenção a realidade dos cuidadores, principalmente no que se refere a pacientes idosos, cabendo aos médicos de família em atendimento domiciliar cuidar, não só dos pacientes, mas também de seus cuidadores.

Historicamente a responsabilidade pelos cuidados na família é da mulher. Segundo Pimenta et. al. (2009), o cuidado do idoso sempre foi exercido por mulheres, principalmente, esposas, filhas e netas. Este cuidado se estende para o marido, os filhos e outros familiares.

No estudo de Montefusco et. al. (2011), 100\% dos cuidadores principais eram do sexo feminino. Os cuidados desenvolvidos pelas mulheres se constituem em aprendizado adquirido social e culturalmente, não questionado pelas próprias mulheres ou suas famílias. Como esse papel não foi escolhido, mas incorporado, ele se constitui em fonte de sofrimento, desprazer e conformismo, embora esses fatores possam comprometer a qualidade do cuidado.

Segundo Párraga, Diaz (2005), cuidadores são aqueles que se ocupam em suprir as necessidades de autocuidado e atenção aos indivíduos portadores de um certo grau de dependência, em um intervalo de tempo que pode variar de diário e continuo até um longo período de tempo. O cuidador é quem assume a responsabilidade de cuidar, dar suporte ou assistir alguma 
necessidade de um indivíduo cuidado, objetivando a melhoria de sua saúde. Portanto, o ato de cuidar envolve o comprometimento de alguém para com outro alguém.

Pode-se classificar duas categorias de cuidadores: o cuidador formal remunerado, que é uma pessoa que geralmente recebe treinamento específico para a função e mantém vínculos profissionais para exercer a atividade de cuidar, e o cuidador informal, pessoa que, tendo relação familiar, de amizade ou vizinhança, se encarrega ou assume os cuidados de um dependente dentro do domicílio. (Born, 2006).

Há outras definições de cuidador principal e secundário, dependendo do grau de envolvimento experimentado por cada um nos cuidados prestados ao idoso dependente. O cuidador principal é aquele que tem total ou maior responsabilidade pelos cuidados prestados ao idoso dependente no domicílio. Os cuidadores secundários seriam os familiares, voluntários e profissionais que prestam atividades complementares. (Diogo, Celim, Cintra, 2005).

Destes cuidadores é cobrado, explícita ou implicitamente, habilidade manual, cama limpa, cumprimento dos horários de tomada dos medicamentos, alimentação apropriada e na hora certa, banho de sol, amor, entre outros. Tal situação pode colocar em risco o próprio ato de cuidar e, consequentemente, a saúde do cuidador. (Almeida, 2005).

$\mathrm{O}$ fato dos idosos apresentarem enfermidade crônica faz com que essas pessoas não possam contar com um período de "férias" dos cuidados, gerando estresse, a menos que a família tenha uma organização tal que permita isso, mas esta situação é muito rara. O cuidador estressado corre risco de transferir sua insatisfação para o paciente, chegando, por vezes, a ser agressivo e intolerante. O cansaço é cumulativo e é desejável que a pessoa consiga descansar após curtos espaços de tempo. (Laham, Silva, 2006).

As doenças agudas e sem risco de morte provocam poucas alterações emocionais e comportamentais na família. Já as mais graves, provocam alterações mais profundas, tais como: ansiedade, estado de choque, negação, raiva e isolamento. (Potter, Perry, 2005). 
As sobrecargas físicas e psíquicas a que os cuidadores de idosos estão expostos levam à má qualidade de vida desses indivíduos, com impacto negativo resultante da qualidade de vida do próprio idoso. As consequências mais comuns do impacto de cuidar são os problemas sociais, econômicos, piora da saúde física e psicológica. (Paula, Roque, Araújo, 2008).

Cuidadores sobrecarregados e desgastados têm a manutenção de qualidade de vida ameaçada devido ao estresse, advindo da responsabilidade de cuidar, apresentando, em muitas situações, sentimentos de impotência, problemas de saúde, cansaço e irritabilidade. (Souza, Wegner, Gorini, 2007).

Cuidar de idosos dependentes traz uma variedade de efeitos adversos e impacto emocional que é vivido por familiares que cuidam de pessoas com doença mental ou outros problemas decorrentes do envelhecimento. Esse impacto emocional ou sobrecarga tem sido definido como: problemas físicos, psicológicos ou emocionais, sociais e financeiros que familiares apresentam por cuidarem de idosos doentes. (Zarit, 1997, Garrido, Almeida;1999 apud Pinto et. al., 2009).

Floriani, Schramm (2006) demonstraram que o comprometimento psicossocial à vida do cuidador traz uma gama variada de achados: depressão, distúrbios do sono, medo, maior uso de psicotrópicos, rupturas de vínculos, isolamento, solidão, diminuição da participação social, perda do suporte social e menor satisfação com a vida, ou seja, uma qualidade de vida debilitada.

Em concordância com as perspectivas epidemiológicas atuais, o apoio formal da família ao idoso é um tema de crescente interesse, já que mais e mais idosos permanecerão na comunidade durante boa parte de sua velhice. O tema sobre a qualidade do relacionamento da díade fornecedor e receptor de cuidados insere-se no campo tradicional de pesquisa em gerontologia. (Trentini et. al. 2006).

Assim sendo, considera-se que se o cuidador recebesse apoio e informação para satisfazer as necessidades práticas e emocionais das tarefas do cuidado, poderia influenciar o seu bem-estar e, consequentemente em sua 
qualidade de vida, visto que a percepção de apoio pode amenizar as tensões associadas à dependência do idoso, possibilitando manter o equilíbrio de saúde no cuidador que, por sua vez, terá melhores condições para atender o idoso fragilizado (Guedea et.al. 2009).

Estudar a Qualidade de Vida dos cuidadores é um tema de importância para planejar ações integrais para sua saúde com objetivo de minimizar os efeitos da sobrecarga de cuidado vivenciada por eles.

\title{
1.3 QUALIDADE DE VIDA
}

A Organização Mundial de Saúde (OMS), em 1995 definiu que: "Qualidade de vida é a percepção do indivíduo de sua inserção na vida no contexto da cultura e sistemas de valores nos quais ele vive e em relação aos seus objetivos, expectativas, padrões e preocupações".

Segundo Minayo (2000):

\begin{abstract}
"Qualidade de vida é uma noção eminentemente humana, que tem sido aproximada ao grau de satisfação encontrado na vida familiar, amorosa, social e ambiental e à própria estética existencial. Pressupõe a capacidade de efetuar uma síntese cultural de todos os elementos que determinada sociedade considera seu padrão de conforto e bem-estar. O termo abrange muitos significados, que refletem conhecimentos, experiências e valores de indivíduos e coletividades que a ele se reportam em variadas épocas, espaços e histórias diferentes, sendo, portanto uma construção social com a marca da relatividade cultural."
\end{abstract}

O uso das medidas de qualidade de vida (QV) é relevante na avaliação de saúde, tanto na perspectiva social quanto individual, sobretudo nos quadros de doenças degenerativas, em que a mensuração da eficácia do tratamento se traduz na QV dos anos vividos, mesmo na ausência de cura (Paula, Roque, Araújo, 2008).

Vários instrumentos têm sido desenvolvidos no mundo inteiro com o objetivo de avaliar a QV das populações (instrumentos genéricos) ou direcionados a grupos de indivíduos que sofrem de alguma doença aguda ou crônica (instrumentos específicos). (Paulo et.al. 2008).

Com a finalidade de nomear um instrumento genérico, tendo como 
base à definição de QV da OMS, pesquisadores ligados a esta mesma organização apoiaram uma avaliação, construída sob enfoque transcultural, a qual parte do pressuposto que a QV é um constructo subjetivo, multidimensional e composto por dimensões positivas e negativas. Devido a estas características, o questionário denominado World Health Organization Quality Of Life (WHOQOL) tem sido um dos mais utilizados e traduzidos no mundo, considerando-se quatro domínios: físico, psicológico, relações sociais e meio ambiente. (Paulo et. al. 2008).

Em uma revisão integrativa, realizada em 2011 e apresentada como painel no $2^{\circ}$ Simpósio Internacional de Políticas e Práticas em Saúde Coletiva na Perspectiva da Enfermagem, norteada pela pergunta "Quais são as evidências que têm sido descritas na literatura sobre a QV de cuidadores familiares de idosos dependentes?". Realizou-se um levantamento bibliográfico nas bases de dados LILACS, Scielo e MEDLINE. Foram encontrados 289 artigos e destes, 15 estavam relacionados ao tema proposto. A maioria avaliou a QV de cuidadores de idosos com Alzheimer e os instrumentos utilizados foram: QV Alzheimer cuidador, SF36, PDQ 39, WHOQOL-Bref.

Esses estudos apontaram que a maioria dos cuidadores de idosos eram mulheres, com idade mais avançada, normalmente membro da família, sendo, portanto, considerado cuidadores informais e, assim, apresentaram uma pior QV e diminuição da vida social.

A investigação sobre a QV dos cuidadores de idosos acamados é um tema que já despertou interesse de vários pesquisadores. No entanto, ainda há necessidade de mais estudos sobre o tema, buscando melhores soluções para a promoção de saúde desses cuidadores.

\subsection{A FISIOTERAPIA E A QUALIDADE DE VIDA DO CUIDADOR}

Como estagiária de Fisioterapia desde 2005 e, após a formatura em 2007, trabalhando na Unimed Alfenas, no Programa de Medicina Preventiva na Assistência Domiciliar no Projeto SOL (Serviços de Orientação no Lar), 
na Unimed de Poços de Caldas, percebi a necessidade de olhar para os cuidadores de idosos, principalmente, aqueles que cuidam de idosos acamados, com uma maior dependência e demanda de cuidados.

Observando o grande despreparo tanto físico quanto emocional dos cuidadores para acolher um idoso dependente e o esforço da equipe de saúde em atender uma demanda crescente, despertou-se a necessidade de olhar para estes cuidadores que, assim como os pacientes debilitados, também necessitam de assistência e orientações. Em consequência a esta realidade, surgiu o interesse em realizar uma análise da QV, considerando que existem poucos estudos em cuidadores de idosos voltados à fisioterapia.

A fisioterapia não deve ser apenas reabilitadora, mas, principalmente, preventiva e preocupada com a compreensão do processo de saúde-doença e todas as consequências dessa interação (Almeida, 2005).

O fisioterapeuta em trabalho no domicílio deve atuar na recuperação, prevenção de incapacidades e/ou doenças e na promoção da saúde, intervindo não só no indivíduo, mas também no coletivo, programando ações que considerem os aspectos sociais, econômicos, culturais e ambientais que possam intervir no processo saúde-doença.

Ou seja, o papel fundamental da fisioterapia no restabelecimento dos idosos acamados em seus domicílios e de seus cuidadores está em focar não somente a saúde do idoso, mas também de seu cuidador.

As visitas domiciliares devem ter uma abordagem familiar, não centrada apenas no idoso, mas compartilhar a responsabilidade da intervenção com todos os membros, principalmente com o cuidador principal, que fica com o idoso quase que em tempo integral, buscando ações mais eficientes e próximas da realidade da família. (Veras et. al. 2004 apud Aveiro et.al. 2011)

As atividades de cuidar de um idoso acamado levam a desgastes físicos, que se bem orientados podem ser amenizados. Porém, a falta de informação e de pesquisas voltadas sobre os benefícios da fisioterapia domiciliar em determinados grupos, tem dificultado a ação eficiente de ampliação e promoção desse tipo de atendimento.

As publicações têm mostrado a grande preocupação na reabilitação e 
cuidados fisioterápicos com os indivíduos acamados, especialmente os crônicos e dentre eles os idosos, enfocando a reabilitação motora e ventilatória, o que pouco se observa em relação aos cuidadores, focando a prevenção de agravos físicos-posturais, principalmente àqueles que exercem longo tempo de cuidado.

Pelo contexto geral, ora explanado, surgem algumas indagações:

- Os cuidadores de idosos estão preparados tanto físico, como emocionalmente para atender as demandas de um idoso acamado?

- Como estará a saúde destes cuidadores em sua velhice?

- Como o fisioterapeuta pode estar atuando junto com uma equipe multiprofissional para dar suporte a estes cuidadores?

Frente a estes questionamentos e ao pequeno número de pesquisas nesta área, o presente estudo propõe-se a analisar a QV dos cuidadores principais de idosos acamados, visando colaborar na prevenção de potenciais agravos com doenças crônicas degenerativas, causadas pela sobrecarga física e emocional nas atividades do cuidar.

Pretende-se com isso contribuir para o desenvolvimento de atividades integradas preventivo-reabilitadoras e curativas, foco principal da atuação da fisioterapia, junto com uma equipe multidisciplinar e, consequentemente, promover uma melhor QV para os idosos restritos ao leito e seus cuidadores. 


\subsection{OBJETIVOS}

\subsection{OBJETIVO GERAL}

Verificar a QV dos cuidadores de idosos restritos ao leito pertencentes ao Programa de Medicina Preventiva da Unimed de Poços de Caldas.

\subsection{OBJETIVOS ESPECÍFICOS}

- Conhecer o perfil dos cuidadores de idosos.

- Verificar as modificações na saúde do cuidador após as atividades de cuidar do paciente idoso.

- Comparar a qualidade de vida dos cuidadores formais com a dos cuidadores informais. 


\section{METODOLOGIA}

\subsection{TIPO DO ESTUDO}

O presente trabalho apresenta uma abordagem quantitativa, dentro de um estudo transversal, exploratório e descritivo.

Abordagem quantitativa significa quantificar opiniões, dados, nas formas de coleta de informações, utilizando recursos e técnicas estatísticas. É comum ser empregada no desenvolvimento de pesquisas descritivas, em que se procura descobrir e classificar a relação entre variáveis, assim como na investigação da relação de causalidade entre os fenômenos: causa e efeito (Oliveira, 2000).

Pesquisa descritiva são fatos observados, registrados, analisados, classificados e interpretados, sem interferência do pesquisador, com o uso de técnicas padronizadas de coleta de dados - questionário e observação sistemática (Rodrigues, 2007).

\subsection{LOCAL DO ESTUDO}

O presente estudo foi realizado junto ao Projeto da Medicina Preventiva, Projeto SOL ("Serviços de Orientação no Lar"), da Unimed de Poços de Caldas. O Projeto SOL é o único da cidade que tem um programa de assistência domiciliar sistematizado, ou seja, é o único que mantém uma frequência de visitações domiciliares e abrange toda a cidade, por isso, foi escolhido.

O Projeto SOL atende 167 pacientes. Destes, 52 são idosos restritos ao leito que necessitam de um cuidador para assistência diária.

Os pacientes do projeto recebem, além de cuidados especiais, orientações multidisciplinares, que visam dar continuidade à assistência médico-hospitalar aos usuários em seu próprio lar, possibilitando sua reinserção no meio familiar e social.

O Projeto proporciona conforto e segurança aos usuários, reduz 
custos da cooperativa com despesas hospitalares, promove suporte a pacientes portadores de doenças crônicas, prevenindo complicações. Também oferece suporte a pacientes terminais e suas famílias, melhorando a qualidade de vida. Os pacientes recebem alta precoce, diminuindo o risco de infecções hospitalares, e são estimulados a serem independentes, segundo limitações particulares, permitindo a reintegração no meio social.

\section{Os aspectos positivos deste projeto são:}

- Para o paciente: proporciona uma melhor qualidade de vida, reduz o risco de infecções hospitalares, evita internações frequentes e repetitivas e evita a perda do vínculo familiar.

- Para a cooperativa: diminuição dos custos relativos a pacientes que estariam hospitalizados, uma vez que os números de diárias são reduzidas, quer seja com a transferência antecipada do paciente do hospital para a residência, quer seja evitando-se uma internação. É uma estratégia de marketing, tendo como propaganda positiva a satisfação do usuário e consequente inclusão de novos.

- Para o hospital: otimização do giro/leito com a retirada de pacientes com doenças crônico-degenerativas e pós-operatórios prolongados.

\section{Campos de atuação:}

a) Suporte a pacientes portadores de patologias crônicas, degenerativas e sequelados.

b) Atendimento a pacientes com possibilidades de alta hospitalar precoce. Indicado para usuários que tenham condições de dar continuidade e finalizar o tratamento em casa.

c) Recém-nascidos, para controle de peso e fototerapia.

\section{Atividades desenvolvidas:}

- Atendimento Domiciliar

- Internação Domiciliar

- Acompanhamento Domiciliar

- Monitoramento com visita ou telefonema, para satisfação do cliente e 
controle de custos do programa (Assistência Social - SIM).

A Equipe Sol é composta de: médico do paciente, assistente social, enfermeira, auxiliar de enfermagem, infectologista, nutróloga, fisioterapeuta, estagiários de fisioterapia e psicóloga.

Poços de Caldas possui uma população fixa de 152.496 habitantes, sendo o município mais populoso do sul de Minas Gerais. Sua população flutuante é de 225.580 habitantes, área de $545,7 \mathrm{~km}^{2}$ e densidade demográfica de 264,58 hab./ $\mathrm{km}^{2}$. O município fica situado em uma região vulcânica já extinta, no sopé da Serra de São Domingos, região Sudoeste do Estado de Minas Gerais. Pertence à região administrativa do Alto do Rio Pardo, tendo como limites Bandeira do Sul e Botelhos ao norte, Andradas ao Sul, Caldas a leste e a oeste Águas da Prata, pertencente essa ao Estado de São Paulo (Prefeitura de Poços de Caldas, 2011).

Poços de Caldas possui uma longa tradição como centro de cuidados com a saúde. Essa tradição é destacada no nome de sua padroeira "Nossa Senhora da Saúde" e no lema de sua bandeira "Salus et Vita". O seu potencial turístico vem há anos sendo divulgado pelo slogan "Terra da Saúde e da Beleza" (Siqueira, 2000).

A história de Poços de Caldas começou a ser escrita a partir da descoberta de suas primeiras fontes e nascentes, no século XVII, encontradas no fundo de um vulcão de 85 milhões de anos atrás. As águas raras e com poderes de cura foram responsáveis pela prosperidade do município desde os seus primórdios, quando as terras começaram a ser ocupadas por ex-garimpeiros (Siqueira, 2000).

Somente em 1872, com a doação de quarenta alqueires de terra pelo Major Joaquim Bernardes da Costa Junqueira, dá-se início à construção da futura cidade, denominada "Nossa Senhora da Saúde das Águas de Caldas" (Siqueira, 2000).

Desde 1886, funciona no município uma casa de banho, utilizada para tratamento de doenças cutâneas, sendo um tratamento com água sulfurosa e termal da Fonte dos Macacos. Na década de 30, foi construído o complexo termal formado pelas Thermas Antônio Carlos e o Balneário Dr. 
Mário Mourão. (Siqueira, 2000).

No trecho abaixo, Mário Mourão cita de uma forma poética a importância das águas medicinais de Poços de Caldas para os idosos.

"A água da Juvência no Brasil, a fonte dos velhos, onde adquirem vitalidade, bebendo copos e copos de mocidade" Mourão (1945).

O Gráfico abaixo mostra a pirâmide etária da população de Poços de Caldas, segundo o Censo Demográfico de 2010.

Gráfico 3- Pirâmide etária de Poços de Caldas, 2010.

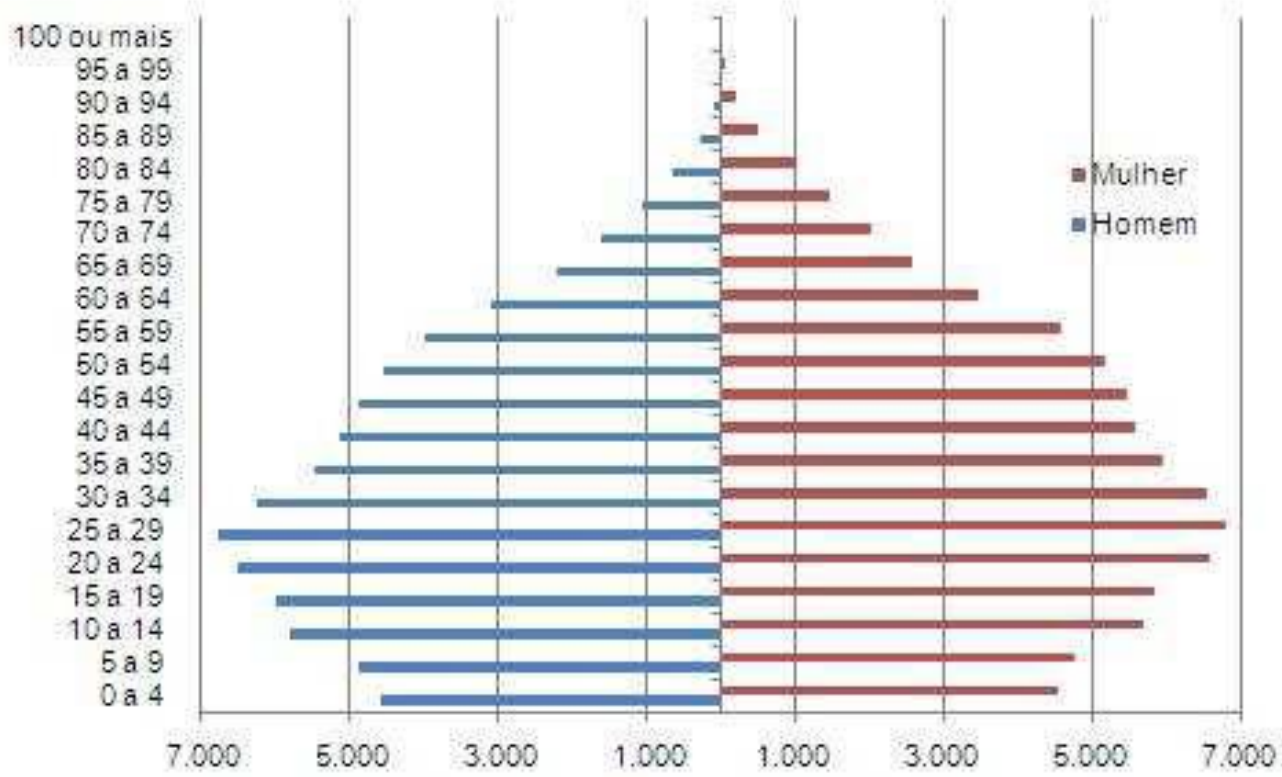

Fonte: Prefeitura de Poços de Caldas, 2011.

A maior parte da população de Poços de Caldas encontra-se na faixa etária de 10 a 40 anos. Entretanto, apresenta uma população cada vez mais envelhecida.

\subsection{POPULAÇÃO DO ESTUDO}

Cuidadores de idosos restritos ao leito integrantes do Programa de Medicina Preventiva da Unimed de Poços de Caldas - Projeto SOL Serviços de Orientações no Lar, que estejam de acordo em participar deste 
estudo e que atendam aos seguintes critérios:

\subsubsection{Critérios de inclusão}

- Ser cuidador principal de idosos integrantes do estudo. Entende-se como cuidador principal aquele que tem total ou maior responsabilidade pelos cuidados prestados no domicílio.

- Ser cuidador de idoso restrito ao leito por no mínimo seis meses.

- Ser capaz de comunicar-se verbalmente.

- Ser alfabetizado, para responder ao WHOQOL-Bref.

\subsection{INSTRUMENTOS}

Para coleta de dados foram utilizados dois instrumentos, a saber:

1. Identificação dos Cuidadores de Idosos acamados/dependente, (Apêndice I), contendo duas partes:

A. perfil do idoso acamado: idade, peso, sexo, estado civil, diagnóstico que determinou que se tornasse acamado/dependente.

B. perfil do cuidador: com dados sócio demográficos, como idade, sexo, estado civil, escolaridade e dados sobre a situação de cuidar; relação que o cuidador tem com o idoso (cuidador formal ou informal), como aprendeu a cuidar; alguns dados sobre sua saúde física, como presença de dores a realizar as tarefas do cuidar, uso de medicações específicas para dores; atividades que o cuidador faz para se autocuidar.

Este instrumento foi criado pela pesquisadora, com a supervisão de sua orientadora. Para sua validação e ajustes necessários, inicialmente foi testado em cinco cuidadores, que não fizeram parte da amostra. 
2. O Questionário WHOQOL Bref (Anexo1). Analisou a qualidade de vida. Este instrumento foi testado e validado para ser aplicado em nosso meio (Fleck et.al. 2000).

"O WHOQOL-Bref consta de 26 questões, sendo duas questões gerais e as demais 24 representam cada uma das 24 facetas que compõe o instrumento original." (Fleck et. al. 2000).

"Assim, diferente do WHOQOL-100 em que cada uma das 24 facetas é avaliada a partir de quatro questões, no WHOQOL-Bref é avaliada por apenas uma questão" (Fleck et.al. 2000).

\begin{abstract}
"O critério de seleção das questões para compor o WHOQOL-bref foi tanto psicométrico como conceitual. No nível conceitual, foi definido pelo Grupo de Qualidade de Vida da OMS de que o caráter abrangente do instrumento original (o WHOQOL-100) deveria ser preservado. Assim, cada uma das 24 facetas que compõem o WHOQOL-100 deveria ser representada por uma questão. No nível psicométrico foi então selecionada a questão que mais altamente se correlacionasse com o escore total do WHOQOL-100, calculado pela média de todas as facetas. Após esta etapa, os itens selecionados foram examinados por um painel de peritos para estabelecer se representavam conceitualmente cada domínio de onde as facetas provinham. Dos 24 itens selecionados, seis foram substituídos por questões que definissem melhor a faceta correspondente. Três itens do domínio meio ambiente foram substituídos por serem muito correlacionados com o domínio psicológico. Os outros três itens foram substituídos por explicarem melhor a faceta em questão.” (Fleck et.al. 2000).
\end{abstract}

Assim o WHOQOL-Bref é um questionário autoaplicável, composto por quatro domínios: Físico, Psicológico, Relações Sociais e Meioambiente e estão descritas no Anexo 2.

Para análise de frequências e medidas descritivas das questões a pontuação é dada em uma escala do tipo LIKERT, de um a cinco, onde um e dois representam uma avaliação negativa, três intermediária e quatro a cinco representam uma avaliação positiva (Fleck, 2000).

\title{
3.5 VARIÁVEIS DO ESTUDO
}

\subsubsection{As variáveis independentes sócio-demográficas e econômicas consideradas neste estudo foram:}


- Sexo: Masculino ou Feminino

- Idade: categorizada por faixa etária de: 40 a 49, 50 a 59, 60 a 69, 70 a 79 e mais de 80 anos.

- Estado Civil: solteiro, viúvo e casado.

- Escolaridade: $1^{\circ}$ Grau (Ensino Fundamental), $2^{\circ}$ Grau (Ensino Médio) e $3^{\circ}$ Grau (Ensino Superior).

- Diagnóstico do paciente: Mal de Alzheimer, Mal de Parkinson, Acidente Vascular Encefálico, fratura de fêmur, síndrome de Shy Dryger, paralisia cerebral, amputação de membro inferior, fratura de fêmur e doença de Fahr.

\subsubsection{As variáveis dependentes deste estudo foram:}

- Cuidadores: informais ou formais

- Como aprendeu a cuidar do idoso: sozinho, ajuda profissional, cursos e outros.

- Se sente dores no corpo ao cuidar do idoso: sim ou não

- Se a dor permanece após os cuidados com o idoso: sim ou não

- Se faz alguma terapia para amenizar as dores: sim ou não

- Se transfere o idoso: sim ou não

- Quantas vezes por dia transfere o idoso: 1 a 3, 4 a 6 ou mais de 10 vezes.

- Se pratica atividade física ou auto cuidado: sim ou não

\subsection{COLETA DE DADOS}

Primeiramente foi feito uma investigação nos prontuários dos pacientes registrados na Unimed para identificar os pacientes idosos acamados. Todos foram entrevistados na residência do idoso, após agendamento prévio pelo telefone.

As entrevistas, com duração de aproximadamente 40 minutos, foram realizadas nos meses de novembro de 2012 a fevereiro de 2013 pela 
pesquisadora. O Termo de Consentimento (TCLE) - Apêndice II - foi devidamente explicado e, após o entendimento do cuidador, foi assinado, ficando uma cópia com o cuidador e uma cópia com o pesquisador.

A seguir da aplicação do questionário sobre os aspectos sóciodemográficos, foi pesquisado o impacto físico e/ou psicológico do cuidar de um idoso acamado e analisado a QV dos cuidadores, utilizando o questionário com os quatro domínios do WHOQOL - Bref.

\subsection{PROCEDIMENTOS ÉTICOS PARA A REALIZAÇÃO DA PESQUISA}

O projeto de pesquisa foi submetido à apreciação do Comitê de Ética em Pesquisa da Escola de Enfermagem da Universidade de São Paulo, de acordo com exigências da Resolução 196/96, $\mathrm{n}^{\circ}$ do CAAE 05904012100005392 (Anexo IV).

Atendendo à mesma Resolução, todos os cuidadores de idosos participantes deste estudo, cujas identidades foram preservadas, receberam informações sobre a pesquisa e após concordarem em participar da pesquisa, leram e assinaram o Termo de Consentimento Livre e Esclarecido (Apêndice II)

Foi solicitado, também, autorização ao Diretor Presidente da Unimed Poços de Caldas (Apêndice III), para a realização da pesquisa com cuidadores principais de idosos restritos ao leito, residentes na cidade de Poços de Caldas, cadastradas e atendidas pelo Projeto SOL - Serviços de Orientações no Lar.

\subsection{ANÁLISE DOS DADOS}

A análise dos dados foi feita através da apresentação dos resultados em tabelas de distribuições de frequência absoluta e relativa. A partir dos dados agrupados, foram estimadas as medidas de tendência central (média) e medidas de dispersão. 
Para analisar o questionário "WHOQOL-Bref" foram utilizados os escores, baseados no programa estatístico SPSS (Statistical Package for Social Sciences) e segue as expressões matemáticas padronizadas, conforme sintaxe apresentada no Anexo III.

A análise dos dados coletados foi feita com base no referencial teórico adotado, relacionando as proposições sobre envelhecimento, o cuidado e o cuidar, qualidade de vida, medidas preventivas de saúde.

Os dados foram apresentados de forma descritiva, os resultados foram confrontados entre si e com a literatura de referencial teórico. 


\section{RESULTADOS E DISCUSSÃO}

Do universo de 52 sujeitos, seis cuidadores não aceitaram serem entrevistados e dois eram analfabetos, deste modo foram excluídos, de acordo com os critérios pré-estabelecidos. Portanto, foram entrevistados 44 cuidadores de idosos restritos ao leito que necessitam de um cuidador para cuidados diários, atendidos no Projeto de Serviços de Orientação no Lar (SOL) da Unimed de Poços de Caldas.

Para facilitar a apresentação e discussão os mesmos foram divididos em dois tópicos: 1. Caracterização da população estudada; 2. Análise das condições físicas e da qualidade de vida.

Serão apresentadas ao longo do texto algumas colocações dos sujeitos entrevistados, para ilustração dos sentimentos expressados durante as entrevistas.

\subsection{CARACTERIZAÇÃO DA POPULAÇÃO ESTUDADA}

Para compreender o cotidiano da população de cuidadores, é importante conhecer as características da população de idosos assistidos por ela, considerando que refletem diretamente na saúde e qualidade de vida deles.

\subsubsection{Idosos assistidos pela população de cuidadores}

A idade média dos idosos assistidos pelos cuidadores é de 82 anos, tendo um desvio padrão de 11,3, o que caracteriza uma população de idosos velhos.

Em países em desenvolvimento, idosos são aqueles indivíduos pertencentes à idade de 60 anos ou mais, tendo três divisões: entre 60 e 69 idosos jovens, entre 70 e 79 idosos e aqueles com idade igual ou superior a 80 anos, idosos velhos ou em velhice avançada. Na França tem-se utilizado o termo "quarta idade". (Berquó, 1996 apud Braz, 2008). 
Neste estudo, verificou-se a predominância de idosos do sexo feminino assistidos pelos cuidadores, correspondendo a 65,90\% (29) e $34,09 \%$ (15) do masculino (Tabela 1). Esses dados corroboram o estudo de Camarano (2003), que relata a "feminização da velhice", dada pela menor mortalidade feminina.

Tabela 1 - Caracterização dos idosos assistidos pelo Projeto SOL da Unimed de Poços de Caldas assistidos pela população de cuidadores. Poços de Caldas, 2012.

\begin{tabular}{clllllll}
\hline VARIÁVEIS & \multicolumn{3}{l}{ Masculino } & \multicolumn{2}{l}{ Feminino } & \multicolumn{2}{l}{ Total } \\
& $\mathbf{N}^{\circ}$ & $\boldsymbol{\%}$ & $\mathbf{N}^{\circ}$ & $\boldsymbol{\%}$ & $\mathbf{N}^{\circ}$ & $\%$ \\
\hline IDADE & & & & & & \\
$60-69$ & 5 & 11,36 & 3 & 6,81 & 8 & 18,18 \\
$70-79$ & 4 & 9,09 & 5 & 11,36 & 9 & 20,45 \\
$\geq 80$ & 6 & 13,63 & 21 & 47,72 & 27 & 61,36 \\
Sub Total & $\mathbf{1 5}$ & $\mathbf{3 4 , 0 9}$ & $\mathbf{2 9}$ & $\mathbf{6 5 , 9 0}$ & $\mathbf{4 4}$ & $\mathbf{1 0 0}$
\end{tabular}

ESTADO CIVIL

$\begin{array}{lllllll}\text { Solteiro } & 2 & 4,54 & 2 & 4,54 & 4 & 9,09 \\ \text { Casado } & 13 & 29,54 & 3 & 6,81 & 16 & 36,36 \\ \text { Viúvo } & 0 & 0 & 24 & 54,54 & 24 & 54,54\end{array}$

\section{DIAGNÓSTICO}

$\begin{array}{lllllll}\text { Mal de Alzheimer } & 3 & 6,81 & 14 & 31,81 & 17 & \mathbf{3 8 , 6 3} \\ \text { Mal de Parkinson } & 1 & 2,27 & 2 & 4,54 & 3 & 6,81 \\ \text { Fratura de Fêmur } & 2 & 4,54 & 1 & 2,27 & 3 & 6,81 \\ \text { Síndrome de Shy Dryger } & 1 & 2,27 & 0 & 0 & 1 & 2,27 \\ \text { Paralisia Cerebral } & 1 & 2,27 & 1 & 2,27 & 2 & 4,54 \\ \text { Acidente Vascular Encefálico } & 4 & 9,09 & 11 & 25 & 15 & \mathbf{3 4 , 0 9} \\ \text { Doença de Fahr } & 1 & 2,27 & 0 & 0 & 1 & 2,27 \\ \text { Amputação de Membro Inferior } & 2 & 4,54 & 0 & 0 & 2 & 4,54\end{array}$

A idade dos idosos assistidos varia de 60 a 105 anos, sendo que a maior incidência foi encontrada na faixa de 80 anos ou mais com $61,36 \%$ 
(27), principalmente nas mulheres, nas quais esse índice foi de 47,72\% (21), e dos homens 13,63\% (6) (Tabela 1). Segundo o Censo Demográfico de 2000 , por exemplo, $55 \%$ do contingente populacional brasileiro maior de 60 anos eram compostos por mulheres. Entre os maiores de 80 anos, essa proporção sobe para $60,1 \%$.

Em 2001 as mulheres tinham uma expectativa de vida de oito anos a mais que dos homens (respectivamente 73 e 65 anos). (OPS, 2003 apud Laurent, Jorge, Gotlieb, 2005). Fato que se explica por questões biológicas, pois apresenta o fator de proteção conferido por hormônios femininos em relação à isquemia coronariana. Há também agravos à saúde, ligados a comportamentos específicos do homem e da mulher, que dependem de fatores culturais e sociais. (Laurent, Jorge, Gotlieb, 2005).

Quanto ao estado civil dos idosos, 29,54\% (13) dos homens são casados, nenhum viúvo e apenas 4,54\% (2) são solteiros, sendo que esses solteiros apresentam doenças crônicas desde a infância, como Paralisia Cerebral e Doença de Fahr, sendo antes cuidados pela mãe e, agora pelas irmãs. Grande parte das mulheres são viúvas 54,54\% (24), dado que reafirma a "feminização da velhice"; 6,81\% (3) casadas e 4,54\% (2) solteiras (Tabela 1).

De acordo com Salgado (2002) existe maior número de viúvas que de viúvos, justificados pelo maior número de recasamentos de homens idosos com mulheres mais jovens.

O diagnóstico mais frequente entre os idosos foi de Doença de Alzheimer (DA) 38,63\% (17), sendo 31,81\% (14) mulheres e 6,81\% (3) homens (Tabela 1). Estes dados corroboram o estudo de Pinto et. al (2009) que relata que a Doença de Alzheimer é mais frequente no gênero feminino (Tabela 1).

O Acidente Vascular Encefálico (AVE) representa a segunda maior causa de dependência neste estudo, sendo a prevalência de 34,09\% (15), dos quais 25\% (11) eram mulheres e 9,09\% (4) homens (Tabela 1). Alguns cuidadores disseram que os idosos sofreram o AVE devido ao estilo de vida que levavam antes, como: bebidas, cigarros, má alimentação. Outros 
afirmaram que os idosos não aderiram ao tratamento de Hipertensão Arterial.

Os outros diagnósticos que levaram os idosos a estarem acamados, de acordo com dados da Tabela 1, foram: Mal de Parkinson em estágio avançado 6,81\% (3), fratura de fêmur após queda 6,81\% (3), Paralisia Cerebral diagnosticada na infância 4,54\% (2), amputação de Membro Inferior devido às complicações da diabetes mellitus 4,54\% (2), sendo que este diagnóstico foi apenas encontrado nos homens e as cuidadoras (esposas) disseram que os idosos fumavam muito antes da amputação, Síndrome de Shy Dryger 2,27\% (1), doença rara e Doença de Fahr 2,27\% (1).

Os dados acima mostram que todas as doenças instaladas nos idosos do estudo são crônicas, sendo estas, em sua maioria, degenerativas e incapacitantes, o que traz a necessidade de cuidadores por toda a vida para auxílio nas Atividades de Vida Diária (AVD).

\footnotetext{
"As condições agudas, em geral, apresentam um curso curto, inferior a três meses de duração, e tendem a se autolimitar; ao contrário, as condições crônicas têm um período de duração mais ou menos longo, superior a três meses, e nos casos de algumas doenças crônicas, tendem a se apresentar de forma definitiva e permanente" (Von Korff et.al. 1997, Singh 2008 apud Mendes 2012).
}

Em decorrência do processo de envelhecimento populacional, existe o aumento significativo na prevalência de doenças crônico-degenerativas, o que dificulta ainda mais uma boa interação com a sociedade, especialmente casos de demências, sendo a mais comum a Doença de Alzheimer, como relatam Lemos, Gazzola e Ramos (2006), o que se assemelha aos dados encontrados neste estudo.

O impacto sofrido pelos cuidadores de portadores de DA é observado nos serviços de saúde. Estes cuidadores vão a consultas médicas e utilizam medicamentos psicotrópicos $46 \%$ mais que os cuidadores de pacientes que não têm DA. (Garrido \& Almeida 1999, Grafstrom et.al. 1992, Haley 1997 apud Cruz, Handan 2008).

Entre as enfermidades crônico-degenerativas, as cerebrovasculares representam a terceira causa de morte no mundo, sendo que O AVE 
isquêmico ou hemorrágico, transitório ou definitivo, apresenta maior incidência, tem maior morbidade e resulta em inabilidades (Braga, Alvarenga, Mores, 2003). No estudo, foi a segunda causa que mais provocou a dependência dos idosos.

Para Perlini e Faro (2005), cerca de 40 a 50\% dos indivíduos que sofrem AVE morrem após seis meses. A maioria dos sobreviventes exibirá deficiências neurológicas e incapacidades residuais significativas, o que faz desta patologia a primeira causa de incapacitação funcional no mundo ocidental.

O peso médio das mulheres idosas do estudo é de 58,89 $\mathrm{kg}$ com um desvio padrão de 9,33, e dos homens de 78,96 kg com desvio padrão de 6,64 , o que implica uma grande sobrecarga física para os cuidadores que fazem a transferência, principalmente dos homens. Este dado pode explicar as dores na coluna apontadas pelos cuidadores (Tabela 3), embora tenha sido observada durante a entrevista a má postura dos cuidadores, sendo que grande parte deles apresentavam cifose, ombros e pescoço protusos. Essa postura pode explicar a dor e/ou postura do depressivo.

\subsubsection{Caracterização dos cuidadores dos idosos dependentes}

Para melhor compreender o processo do cuidar, os cuidadores foram analisados em dois grupos: cuidadores informais (CI) e cuidadores formais (CF) que têm alguma relação profissional com o idoso, tendo ou não formação específica para estar atuando como cuidador.

\subsubsection{Cuidadores informais $(\mathrm{CI})$}

São aqueles que não possuem relação profissional com o idoso, ou seja, não recebem uma remuneração para efetuar o cuidado e totalizaram 24 indivíduos.

Os cuidadores informais estavam divididos em: $25 \%$ (6) cônjuges, $58,3 \%$ (14) filhos, $8,3 \%$ (2) netos e $8,3 \%$ (2) irmãos. 
Tais resultados se assemelham com o estudo de Gonçalves et. al. 2006, que coloca as cuidadoras como sendo principalmente as esposas, as filhas e as netas. Tal fato pode ser explicado pela tradição de, no passado recente, mulheres não desempenharem funções fora de casa, justificando sua maior disponibilidade para o cuidado da família. Contudo, essa realidade vem sendo modificada em função da inserção social da mulher que passou a participar progressivamente no mercado de trabalho.

A idade média dos cuidadores informais é de 57 anos, com desvio padrão de 15, variando de 40 a mais de 80 anos, sendo que a maior concentração é observada na idade de 60 a 69 anos (Tabela 2).

\subsubsection{Cuidadores formais (CF)}

São aqueles que têm alguma relação profissional com o idoso, tendo ou não formação específica para estar atuando como cuidador.

Os cuidadores formais têm uma idade média de 48 anos com desvio padrão de 13 , variando de 40 a 79 anos, tendo a sua maioria menos de 59 anos (90\%). (Tabela 2).

\subsubsection{Análise dos dois grupos - CI e CF}

Os cuidadores formais têm o maior contingente na chamada "meia idade", na qual normalmente já apresentam uma vida estruturada, tanto pessoal como profissionalmente, com um total de 90\%, sendo entre 40-49 anos 50\% (10) e entre 50-59 anos 40\% (8) (Tabela 2).

Já os cuidadores informais, metade pertencem à meia idade, sendo entre $40-49$ anos $25 \%$ (6) e $50-59$ anos $25 \%$ (6), e a outra metade pertence à chamada $3^{\circ}$ Idade, com um maior contingente em 60-69 anos com 37,5\% (9) (Tabela 2).

Através do teste de hipótese realizado, utilizando o SPS (Statistical Package for Science) do EXCEL, com nível de significância de 5\%, pode-se afirmar que existe diferença entre a idade dos cuidadores informais e dos cuidadores formais. 
Alguns cuidadores informais tiveram que abandonar sua carreira profissional no auge, para cuidar do parente próximo, ilustrado pelos depoimentos a seguir.

\begin{abstract}
"Abandonei meu emprego no auge de minha carreira. Como sou viúva, meus irmãos colocaram em mim toda responsabilidade de cuidar de nossa mãe. De certa forma, não me arrependo, pois amo minha mãe, mas gostaria que eles me ajudassem." (A.M, 55 anos CI).
\end{abstract}

"A pior coisa disso tudo é cuidar dela sozinha. Trabalhei a vida toda, deixei um trabalho de vinte anos para cuidar dela, já que não podia mudar a realidade dela tive que mudar a minha." (S.G., 54 anos - CI).

Segundo Martins, Ribeiro e Garrett (2003), tais fatores acarretam problemas econômicos constituindo stress secundário além de sentimento de anulação pessoal, isolamento e percepção de incompetência pelo desempenho do papel de cuidador e ausência de reconhecimento de ganhos perante a situação.

Este estudo mostrou maior número de cuidadores senescentes, entre os cuidadores informais, o que gera maior impacto em relação a sua saúde e, segundo Braz, 2008, ao assumir a tarefa de cuidar do idoso, assume mais um encargo, para o qual muitas vezes não se encontra preparada, tanto física como emocionalmente, pois está vivendo seu próprio processo de envelhecimento, tendo seus próprios desgastes físicos e emocionais.

"Desde que meu marido ficou doente, emagreci $8 \mathrm{~kg}$. Pareço ter mais idade do que realmente tenho." (N.F., 67anos - CI).

Hooyman (1996) apud Diogo, Ceolim e Cintra (2005) relataram que:

"Nos Estados Unidos da América, 60\% das cuidadoras primárias de idosos são esposas e $73 \%$ delas possuem idade igual ou superior a 65 anos. Estas pessoas são chamadas "vítimas ocultas", pois convivem com o isolamento, a solidão e a sobrecarga de funções. Além da responsabilidade pelo cuidado nas 24 horas diárias, elas enfrentam o seu próprio envelhecimento e o comprometimento físico, bem como as responsabilidades financeiras e legais. Estas questões interferem no relacionamento conjugal, desencadeiam situações estressantes e problemas de saúde nas cuidadoras". 
Tabela 2- Caracterização dos cuidadores de idosos do Projeto SOL da Unimed de Poços de Caldas assistidos pela população de cuidadores. Poços de Caldas, 2012.

\begin{tabular}{|c|c|c|c|c|c|c|c|c|c|c|}
\hline \multirow{3}{*}{ Variáveis } & \multicolumn{2}{|c|}{ CI } & \multirow{2}{*}{\multicolumn{3}{|c|}{ Total }} & \multicolumn{5}{|c|}{ CF } \\
\hline & $\mathbf{M}$ & $\mathbf{F}$ & & & & & & $\mathbf{F}$ & & Total \\
\hline & $\%$ & $\mathbf{N}^{\circ}$ & $\%$ & $\mathbf{N}^{\circ}$ & $\%$ & $\mathbf{N}^{\circ}$ & $\%$ & $\mathbf{N}^{\circ}$ & $\%$ & $\mathbf{N}^{\circ}$ \\
\hline
\end{tabular}

\section{IDADE}

(ANOS)

$\begin{array}{lllllllllllll}40-49 & 1 & 4,1 & 5 & 20,8 & 6 & 25 & 1 & 5 & 9 & 45 & 10 & 50 \\ 50-59 & 1 & 4,1 & 5 & 20,8 & 6 & 25 & - & - & 8 & 40 & 8 & 40 \\ 60-69 & - & - & 9 & 37,5 & 9 & 37,5 & - & - & 1 & 5 & 1 & 5 \\ 70-79 & - & - & 2 & 8,3 & 2 & 8,3 & - & - & 1 & 5 & 1 & 5 \\ + \text { de } 80 & - & - & 1 & 4,1 & 1 & 4,1 & - & - & - & - & - & -\end{array}$

\section{ESTADO}

CIVIL

$\begin{array}{lllllllllllll}\text { Solteiro } & 1 & 4,1 & 8 & 33,3 & 9 & 37,5 & 1 & 5 & 5 & 25 & 6 & 30 \\ \text { Viúvo } & - & - & 1 & 4,1 & 1 & 4,1 & - & - & 2 & 10 & 2 & 10 \\ \text { Casado } & 1 & 4,1 & 13 & 54,1 & 14 & 58,3 & - & - & 12 & 60 & 12 & 60\end{array}$

ESCOLA-

\section{RIDADE}

$\begin{array}{lllllllllllll}1^{\circ} \mathrm{Grau} & - & - & 12 & 50 & 12 & 50 & - & - & 12 & 60 & 12 & 60 \\ 2^{\circ} \mathrm{Grau} & 2 & 8,3 & 8 & 33,3 & 10 & 41,6 & 1 & 5 & 6 & 30 & 7 & 35 \\ 3^{\circ} \mathrm{Grau} & - & - & 2 & 8,3 & 2 & 8,3 & - & - & 1 & 5 & 1 & 5\end{array}$

A maioria dos cuidadores, tanto informais quanto formais, é do sexo feminino, sendo 91,8\% (22) e 95\% (19) respectivamente (Tabela 2).

Estes dados se assemelham aos de Martins, Ribeiro e Garret (2003), quando colocam que os cuidadores são, em sua maioria, do gênero feminino. Os homens, por sua vez, contribuem com ajuda material e em tarefas externas, como deslocar o paciente para outros ambientes. As mulheres, mesmo quando trabalham fora, assumem também os cuidados 
com os idosos, tendo como consequência a dupla jornada de trabalho. Os depoimentos a seguir ilustram bem esta situação:

\footnotetext{
"Não tenho tempo para mim. Cuido da idosa o dia todo, são 10 horas de trabalho. Chego em casa, tenho que cuidar da casa, dos filhos e do marido. Estou em uma dupla jornada de trabalho." (M.R.Z, 36 anos $\mathrm{CF})$.

"Estou entrando em depressão, não tenho tempo para nada. Minha jornada de trabalho é de 10 horas. Sei que preciso fazer atividade física, ter uma boa alimentação, mas não tenho tempo de ir no médico. Além disso, não ganho o quanto necessito.” (J.A.F., 42 anos - CF).
}

As mulheres cuidadoras costumam sofrer maior impacto, talvez isto seja explicado pelas mulheres assumirem tarefas com o cuidado do idoso, além de ter que gerenciar as tarefas domésticas. (Cassis et.al. ,2007; Dunkin, Anderson-Haley ,1998 apud Pinto et.al., 2009).

O cuidado com membros dependentes da família é determinado pelas trocas intergeneracionais, com fortes características de gênero. Em geral, são as mulheres as mais dependentes de cuidado e as tradicionais “cuidadoras". (Camarano, 2003).

O papel da mulher responsável pelo cuidado é visto como natural, já que este está inserido socialmente no papel de mãe. Tal papel é passado de geração em geração, como um ritual (Caldas, 2004).

A maioria dos cuidadores são casados, sendo: $58,3 \%$ (14) dos CI e $60 \%$ (12) dos $\mathrm{CF}$, porém uma parcela significativa de cuidadores são solteiros, sendo 37,5\% (9) dos CI e 30\% (6) dos CF (Tabela 2).

Estes dados corroboram com os encontrados na pesquisa de Laham (2003), na qual mais da metade dos cuidadores eram casados e pertencentes ao gênero feminino.

Quanto à escolaridade dos cuidadores familiares encontramos: 50\% (12) possuem o $1^{\circ}$ grau, $41,6 \%$ (10) o $2^{\circ}$ grau e $8,3 \%$ (2) o $3^{\circ}$ grau (Tabela 2). E os cuidadores formais: $60 \%$ (12) possuem o $1^{\circ} \mathrm{Grau}, 35 \%$ (7) o $2^{\circ}$ Grau e apenas $5 \%(1)$ o $3^{\circ}$ Grau.

Estes dados mostram que apenas uma pequena porcentagem dos cuidadores tiveram alguma preparação para estarem cuidando dos idosos acamados, sendo estes os que demandam cuidados mais específicos. 
Os fatores que estão relacionados com a diminuição da sobrecarga dos cuidadores são: maior nível de escolaridade e rendas financeiras altas dos cuidadores - grifo nosso (Bocchi, 2004).

A grande parte dos cuidadores, informais e formais, aprendeu a cuidar dos idosos sozinha, sendo $83,3 \%$ (20) e $70 \%$ (14), respectivamente (Tabela 3).

Os cuidadores informais que disseram que aprenderam a cuidar do idoso por ajuda profissional 12,5\% (3) foram orientados pela equipe do Projeto SOL da Unimed (Tabela 3).

A cuidadora que respondeu "outros" 4,16\% (1) aprendeu a cuidar em palestras da Associação Maior Apoio ao Doente de Alzheimer (AMADA), em Campinas. Ela relata que, cada semana, um laboratório visitava a reunião ensinando os cuidados com o idoso. Houve também uma palestra que ensinou o cuidador a se cuidar. Então ela, uma vez por semana, sai para ir ao salão de beleza, tomar um lanche com as amigas e ir ao cinema. Neste dia, deixa uma cuidadora contratada com a mãe e não leva o celular para não ser incomodada. (Tabela 3).

Isto mostra o despreparo desses cuidadores em cuidar dos pacientes. A maioria dos cuidadores formais $70 \%$ (14) é resultado daquela empregada doméstica de confiança, que, quando o idoso ficou doente, "ganhou" as funções de cuidador. Além dos serviços domésticos, atribui-se a ela cuidar do idoso, sem nenhum aumento na remuneração. Os demais $30 \%$ (6) estão distribuídos da seguinte forma: 5\% (1) fez o curso superior de enfermagem, $20 \%$ (4) fizeram técnico em enfermagem e 5\% (1) fez o curso de cuidador de idoso.

\footnotetext{
"Trabalho nesta casa há 24 anos, quando o idoso ficou doente, a família me contratou como cuidadora. Agora tenho que dar conta da casa limpa e dos cuidados com o idoso. Fico muito cansada." (E.D.F., 58 anos - CF).
}

“A utilização de pessoas sem formação específica como mão de obra remunerada para o cuidado, prática comum em nosso meio, em geral recai em pessoas com baixa escolaridade, cuja inserção no mercado de trabalho é feita de maneira irregular" (Braz, 2008, pag. 104). 
Por mais simples que seja a execução de um cuidado, se for feito de forma inadequada, pode acarretar complicações clínicas, além da instalação de quadros iatrogênicos, que certamente culminariam no agravamento de seu estado de saúde (Braz, 2008).

No estudo de Couto (2012), o perfil do cuidador formal foi o de gênero feminino que iniciou a vida laboral no trabalho doméstico infantil, com dificuldade de se escolarizar , tendo uma baixa qualificação e inseriu-se no ramo de cuidador de idosos em situações financeiras emergencias.

Guimarães, Hirata e Sugita (2011), com fontes do PNAD (2007), afirmaram que os cuidadores de idosos no Brasil trabalham sem proteção formal, sendo apenas $24 \%$ com carteira assinada, apresentam baixa escolaridade e baixa remuneração.

Sobre os cursos de cuidadores os mesmos autores colocam ainda:

\begin{abstract}
"No Brasil, não existe uma formação com um diploma sancionado pelo Estado para as "cuidadoras". Existe em funcionamento apenas um curso de nível universitário, com duração de um ano, ofertado pela Escola de Enfermagem da Universidade de São Paulo. Trata-se de uma exceção, pouco conhecida até mesmo pela massa dos trabalhadores do care em São Paulo. Em contrapartida, proliferam cursos oferecidos por agências privadas ou por casas de repouso para idosos, com carga horária não superior a vinte horas semanais (cinco módulos de quatro horas, um módulo por semana). Estes cursos ensinam à "cuidadora" como lidar com os idosos no dia a dia (alimentação, higiene, lazer etc.), fornecem informações sobre as principais doenças (Alzheimer, Parkinson, AVC etc.), bem como orientam sobre a atitude a tomar em caso de acidentes".
\end{abstract}

Ao avaliar as consequências do cuidar na saúde do cuidador, verificamos que $87,5 \%$ (21) dos CI e 70\% (14) dos CF dizem ter dores no corpo durante as atividade do cuidar. A maioria refere que a dor está localizada na coluna, sendo 95,2\% (20) CI e 100\% (14) CF (Tabela 3). 
Tabela 3- A inserção no cuidar dos idosos do Projeto SOL da Unimed de Poços de Caldas assistidos pela população de cuidadores. Poços de Caldas, 2012.

\begin{tabular}{|c|c|c|c|c|c|c|c|c|c|c|c|c|}
\hline \multirow[t]{3}{*}{ Variáveis } & \multicolumn{6}{|c|}{ CI } & \multicolumn{6}{|c|}{$\mathbf{C F}$} \\
\hline & \multicolumn{2}{|c|}{ Masculino } & \multicolumn{2}{|c|}{ Feminino } & \multicolumn{2}{|c|}{ Total } & \multicolumn{2}{|c|}{ Masculino } & \multicolumn{2}{|c|}{ Feminino } & \multicolumn{2}{|c|}{ Total } \\
\hline & $\mathbf{N}^{\circ}$ & $\%$ & $\mathbf{N}^{\circ}$ & $\%$ & $\mathbf{N}^{\circ}$ & $\%$ & $\mathbf{N}^{\circ}$ & $\%$ & $\mathbf{N}^{\circ}$ & $\%$ & $\mathbf{N}^{\circ}$ & $\%$ \\
\hline
\end{tabular}

\section{Como}

aprendeu a

cuidar

\begin{tabular}{|c|c|c|c|c|c|c|c|c|c|c|c|}
\hline Sozinho & 2 & 8,3 & 18 & 75 & 20 & 83,3 & - & - & 14 & 70 & 14 \\
\hline Ajuda & - & - & 3 & 12,5 & 3 & 12,5 & - & - & - & - & - \\
\hline
\end{tabular}

Profissional

Curso

Outros

Dor no corpo

ao cuidar

$\begin{array}{lllllllllllll}\text { Sim } & 2 & 8,3 & 19 & 79,1 & 21 & 87,5 & - & - & 14 & 70 & 14 & 70 \\ \text { Não } & - & - & 3 & 12,5 & 3 & 12,5 & 1 & 5 & 5 & 25 & 6 & 30\end{array}$

\section{Permanência}

da dor

$\begin{array}{lllllllllllll}\text { Sim } & 1 & 4,76 & 19 & 90,4 & 20 & 95,2 & - & - & 13 & 92,8 & 13 & 92,8 \\ \text { Não } & 1 & 4,76 & - & - & 1 & 4,76 & - & - & 1 & 7,14 & 1 & 7,14\end{array}$

Faz alguma

terapia para

amenizar a dor

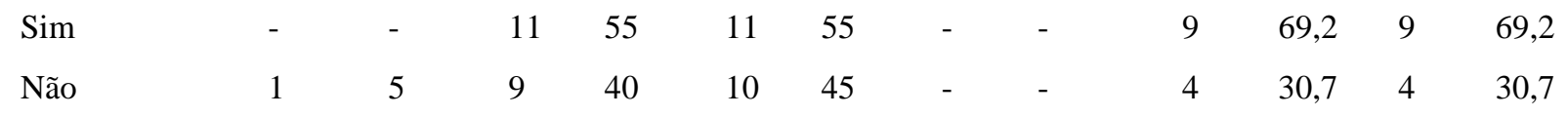

Transfere o

Idoso

$\begin{array}{lllllllllllll}\text { Sim } & 2 & 8,3 & 21 & 87,5 & 23 & 95,8 & 1 & 5 & 17 & 85 & 18 & 90 \\ \text { Não } & - & - & 1 & 4,16 & 1 & 4,16 & - & - & 2 & 10 & 2 & 10\end{array}$

$\mathrm{N}^{\circ}$ de vezes que

transfere

\begin{tabular}{|c|c|c|c|c|c|c|c|c|c|c|c|}
\hline 1 a 3 vezes & 2 & 8,69 & 4 & 17,3 & 6 & 26 & - & - & 3 & 15 & 3 \\
\hline 4 a 6 vezes & - & - & 15 & 65,2 & 15 & 65,2 & 1 & 5 & 15 & 75 & 16 \\
\hline 6 a 10 vezes & - & - & 3 & 13 & 3 & 13 & - & - & 1 & 5 & 1 \\
\hline
\end{tabular}

\section{Pratica}


atividade física

$\begin{array}{lllllllllllll}\text { Sim } & - & - & 2 & 8,33 & 2 & 8,33 & 1 & 5 & 2 & 10 & 3 & 15 \\ \text { Não } & 2 & 8,33 & 20 & 83,3 & 22 & 91,6 & - & - & 17 & 85 & 17 & 85\end{array}$

Auto cuida-se

$\begin{array}{lllllllllllll}\text { Sim } & - & - & 9 & 37,5 & 9 & 37,5 & 1 & 5 & 11 & 55 & 12 & 60 \\ \text { Não } & 2 & 8,33 & 13 & 54,1 & 15 & 65,2 & - & - & 8 & 40 & 8 & 40\end{array}$

Realiza

alongamento?

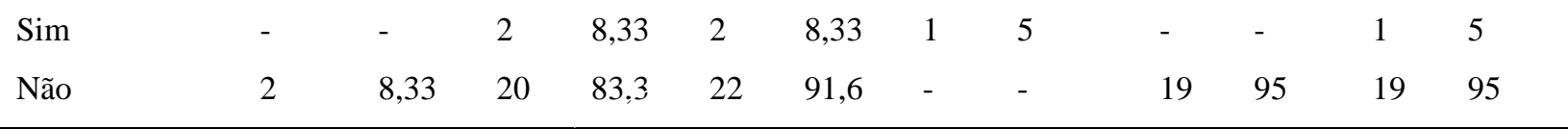

A frequência da dor nos dois grupos mostram a vulnerabilidade dos mesmos, necessitando orientação de profissionais capacitados tanto para aliviar esta sintomatologia como para promover meios para preveni-la.

A dor permanece mesmo após os cuidados do idoso em 95,2\% (20) CI e $92,8 \%$ (13) CF e, desses, 55\% (11) CI e 69,2\% (9) CF se automedicam com analgésicos e anti-inflamatórios (Tabela 3).

Estes dados reforçam a pesquisa de Braz (2008), que afirma que as condições físicas e de saúde relatadas pelos cuidadores levam a inferir que estes também se encontram doentes ou potencialmente doentes. Sendo comum as queixas de dores musculares, dores em membros e da presença de agravos instalados, como hipertensão, cardiopatia e diabetes, doenças essas muito comuns entre os idosos.

Dos 44 cuidadores entrevistados, 95,8\% (23) CI e 90\% (18) CF fazem a transferência dos idosos e apenas $4,16 \%$ (1) CI e $10 \%$ (2) CF não fazem. Porém, estes que não transferem os idosos fazem todos os cuidados diários, como banho de leito, trocar a fralda, dar remédio, entre outros. Todos que fazem a transferência dos idosos sem ajuda de outra pessoa, relataram sentir dores no corpo e que a dor permanece mesmo após o término do cuidados (Tabela 3).

A maioria, $82,60 \%$ (19) CI e $70 \%$ (14) $\mathrm{CF}$, que realiza a transferência dos idosos recebe ajuda de outra pessoa para transferi-los, porém $21,73 \%$ (5) CI e 30\% (6) CF fazem a transferência sozinhos (Tabela $3)$. 
Sobre a frequência de vezes que os cuidadores transferem os idosos, grande parte, $65,2 \%$ (15) CI e $80 \%$ (16) $\mathrm{CF}$, transferem de quatro a seis vezes, sendo este considerado um número alto (Tabela 3 ).

Talvez os dados obtidos sejam um dos motivos dos cuidadores sentirem dores na coluna. A grande maioria não pratica nenhum tipo de atividade física, não estando com uma musculatura preparada para fazer a transferência deste idoso várias vezes por dia, além disso, como já relatado, o idoso é pesado. Essa situação se agrava mais se o idoso estiver com uma musculatura atrofiada e for espático, ou seja, estiver com os membros (superior e/ou inferior) com pouca mobilidade e com rigidez. Também, como quase todos os cuidadores aprenderam a cuidar sozinhos, não possuem instruções de como fazer a transferência dos idosos de forma a não prejudicarem a coluna (Tabela 3 ).

Em relação ao autocuidado, apenas $37,5 \%$ (9) dos cuidadores informais relataram que se cuidam, e 65,2\% (15) responderam que não. Já os cuidadores formais, $60 \%$ (12) afirmaram que se cuidam e $40 \%$ (8) não. (Tabela 3).

Esta diferença entre os dois grupos de cuidadores pode ser explicada pelo fato dos cuidadores informais, $100 \%$ (24) deste estudo, morarem com o idoso, tendo um tempo ainda mais limitado que o cuidador formal para se cuidarem.

Para a maioria dos cuidadores que responderam que se cuidam, resumem isto ao ato de ir ao médico ou fazer exame de rotina. Apenas quatro cuidadores relataram ter uma boa alimentação e uma que viaja uma vez por ano ao exterior, para visitar a filha.

As ações do autocuidado são atividades que o indivíduo desempenha para o seu próprio benefício, para manter-se vivo, saudável e com bemestar. Sendo ações voluntárias e intencionais (Bub et. al. 2006).

Neste estudo, foi considerado o autocuidado desempenhado pelo cuidador as ações de saúde e bem estar, como boa alimentação, atividade física, aderir aos tratamentos médicos necessários e atividades de lazer, como observamos nos seguintes depoimentos. 
“A vida é um exercício de respeito, cada um tem sua missão. Não estamos preparados para enfrentar obstáculos que a vida proporciona. Nós, como cuidadores, também precisamos de acompanhamento médico, psicológico e nutricional. Não tenho tempo de me alimentar corretamente, e com apenas 33 anos já tenho sérios problemas de saúde. Me sinto abandonado pelo sistema público e privado de saúde." (A.F., 33 anos - CI).

"Cuidado que não acaba, e o cuidador tem que se sentir disposto todos os dias, para cumprir com todos os cuidados da forma mais adequada, sempre.” (M.L.M.R., 52 anos - CI).

Para Laham (2003), a necessidade do cuidador praticar o autocuidado e ter consciência dos seus limites pode gerar um medo que não viam em si mesmos.

Muitos cuidadores para cumprir as tarefas do cuidar, acabam descuidando da própria saúde (Almeida, 2005), principalmente sócio emocional, como observamos:

\footnotetext{
"O doente acaba deixando o cuidador mais doente do que ele próprio, pelo trabalho que dá”. (M.A.M, 47 anos - CF).

"Tarefa difícil e dolorosa, mas não pode parar, se não quem que vai cuidar?" (K.S.M., 44 anos - CI).

"Não reclamo de ter deixado minha vida de lado, mas que deixei, deixei." (M.A.B., 55 anos - CI).

"Deixo de ir ao meu médico para ir ao médico dele. Não vou à igreja, nunca saio, nunca viajo, fiquei no esquecimento". (P.P., 66 anos - CI).

"Tenho stress, mas não posso fazer nada, tenho que cuidar do mesmo jeito. Fico, muitas vezes, restrita e gostaria de poder fazer mais, mas não sei como fazer". (R.M.F.B., 57 anos - CI).
}

O resultado mais crítico foi em relação à atividade física, considerando que 91,6\% (22) CI e 85\% (17) CF não fazem atividade física (Tabela 3).

Apenas 8,33\% (2) cuidadores informais praticam atividade física: uma senhora que frequenta duas vezes por semana a Hidroginástica e uma jovem que joga Handboll duas vezes por semana.

E dos cuidadores formais $15 \%$ (3) praticam a atividade física, sendo: uma senhora que pratica Hidroginástica duas vezes por semana, uma jovem 
no pilates duas vezes por semana, e um jovem que é atleta, treinando o atletismo três vezes por semana.

\footnotetext{
"Estou obesa, não tenho tempo de praticar atividade física, e não consigo seguir um regime. Tenho medo de ter a doença de minha mãe." (I.C.M., 29 anos - CI).
}

Outra questão crítica foi em relação ao alongamento, prática de fácil orientação e adoção, em que 91,6\% (22) dos CI e 95\% (19) dos CF não realizam nenhum tipo de alongamento. (Tabela 3 ).

Para Almeida (2005), se forem devidamente orientados para prática de exercícios como alongamento, fortalecimento, caminhadas, atividades de lazer, hidroginástica, entre outras, preveniriam algumas doenças, diminuindo o grau de estresse e isto seria muito útil para auxiliar na realização das atividades que exigem um bom condicionamento físico do cuidador para a sua adequada execução.

O alongamento foi particularmente investigado, pois são exercícios físicos que aumentam o comprimento das estruturas dos tecidos moles e, consequentemente, a flexibilidade. A flexibilidade é tão importante para atletas como para pessoas sedentárias. Uma vez que a amplitude articular de determinada articulação esteja comprometida, alguma limitação se manifestará e poderá comprometer o desempenho esportivo, laboral ou de atividades diárias (Almeida, Jabur, 2007).

Os hábitos posturais estão intimamente ligados à limitação da amplitude articular, da extensibilidade dos músculos e da plasticidade dos ligamentos e tendões. A correção postural e o aumento da amplitude articular, além de ter efeito relaxante, colaboram na tomada de atitudes corporais mais confortáveis, tanto na prática de exercícios quanto nos movimentos diários naturais, além de promover o alívio de tensões musculares.

O uso de exercícios de alongamento para aumentar a flexibilidade é, geralmente, baseado na ideia de que ele pode diminuir a incidência, a intensidade ou a duração da lesão músculo-tendinosa e articular (Almeida, Jabur, 2007). E, em nosso caso, o ato de cuidar exige do cuidador força e 
flexibilidade. Se o cuidador não estiver com um físico apropriado, estará sujeito a lesões músculo-tendíneas e, além disso, sentirá dores musculares frequentes.

Apesar da tarefa de cuidado ser desgastante, muitos cuidadores falaram de forma bastante positiva sobre o ser cuidador, como ilustrado nos depoimentos a seguir.

\footnotetext{
"Aprendi a ser mais paciente, está sendo bom no sentido afetivo, tenho outra visão da vida." (D.A.R., 37anos - CF).

"Faço de tudo com muito amor, não reclamo..." (M.O.L., 48 anos $\mathrm{CF})$.

"Tive muitos aprendizados, como cuidar, ficar atenta para quando ela entra em crise, além disso, dou maior valor à vida." (A.B., 43 anos $\mathrm{CF})$.

"Sempre fui cuidadora. Antes de cuidar do meu marido, cuidava da minha mãe, com isto, aprendi a ser mais humana." (M.H.P.B., 72 anos - CI).

"Cuido do meu avô com muito carinho. Gostaria de cursar o técnico em enfermagem para aprender a cuidar melhor dele, e me profissionalizar nisto." (L.A., 18 anos - CI).
}

Em pesquisa sobre perdas e ganhos que os cuidadores podem ter com o papel que exercem, Laham (2003) encontrou relatos de aspectos positivos e negativos dos cuidados. Entre os positivos, figuram o ganho narcísico, o aprendizado e encontrar um sentido para a vida. Já, entre os negativos, aparecem a perda de liberdade, a solidão e o cansaço.

Verificamos, portanto, que houve modificações importantes na qualidade de vida dos cuidadores.

Os idosos do estudo são acamados, necessitando de cuidados diários e ininterruptos. Esses idosos mais dependentes fisicamente acabam exigindo mais de seus cuidadores, aumentando os desafios e dificuldades no processo de cuidar. Sendo assim, os cuidadores relataram não terem tempo suficiente para o autocuidado, devido à alta carga horária do trabalho de cuidar. Como já relatado, a maioria relatou sentir dores no corpo após as atividades de cuidar e o fato de se automedicarem, podem trazer agravantes, pois se mal administrados, podem levar a sérios danos a saúde. 
O sedentarismo dos cuidadores é preocupante por vários motivos. A atividade física regular é imprescindível para qualquer indivíduo, pois proporciona efeitos benéficos como: melhora do tônus muscular, melhora na flexibilidade, aumento da força muscular, diminuição do LDL (Low Density Lipoproteins), colesterol ruim, aumento do HDL (High Density Lipoproteins), colesterol bom, diminuição do estresse (o trabalho de cuidador geralmente é muito estressante), melhora no humor, prevenção e tratamento de várias doenças crônicas, como hipertensão, diabetes, doenças cardíacas, depressão, entre outras (V Diretrizes Brasileiras de Hipertensão, 2006).

Acresce-se a todos estes fatores a grande sobrecarga emocional dos cuidadores. A angústia por não ver melhora no idoso que está sendo cuidado, medo da perda e do futuro, solidão, isolamento social, frustrações por ter deixado a vida pessoal e social para cuidar, depressão e insônia.

\subsection{CONDIÇÕES FÍSICAS E QUALIDADE DE VIDA DOS CUIDADORES DE IDOSOS}

Como já mencionado a aplicação do WHOQOL-Bref, com o objetivo de analisar quatro domínios da QV: físico, psicológico, relações sociais e meio- ambiente, foi realizada em 44 cuidadores, pois dois cuidadores eram analfabetos e não conseguiram compreender o questionário.

As questões um e dois que tratam respectivamente da QV e satisfação com a vida foram discutidas separadamente e, para verificar se havia diferença nesses quesitos entre o grupo de cuidadores formais e informais, estes foram analisados separadamente.

Pode-se observar que o escore médio da "Qualidade de vida geral", avaliada pela primeira questão foi de 3,46 (69,17\%) para os CI e 3,55 (71\%) para os CF, como apresenta o Quadro 1. Assim os cuidadores de idosos acamados avaliaram sua qualidade de vida como intermediária. 
Sobre a satisfação com a própria saúde, questão 2, o Quadro 1 mostra que os escores apresentados foram de 3,33 (66,67\%) para os CI e 3,25 (65\%) para os CF, sendo considerada como intermediária.

Com o teste de hipótese realizado, utilizando o SPS (Statistical Package for Science) do EXCEL, com nível de significância de 5\%, pode-se afirmar que não houve diferença entre os dois grupos estudados, tanto para o item qualidade de vida, quanto para a satisfação da própria saúde.

Quadro 1- Qualidade de vida dos cuidadores de idosos do projeto SOL da Unimed de Poços de Caldas, 2012.

\begin{tabular}{|c|c|c|}
\hline Facetas da Qualidade de vida & $\begin{array}{l}\text { Valor do escore } \\
\text { CI }\end{array}$ & $\begin{array}{l}\text { médio } \\
\text { CF }\end{array}$ \\
\hline $\begin{array}{l}\text { Como você avaliaria sua qualidade de } \\
\text { vida? }\end{array}$ & 3,70 & 3,55 \\
\hline $\begin{array}{l}\text { Quão satisfeito (a) você está com a sua } \\
\text { saúde? }\end{array}$ & 3,54 & 3,25 \\
\hline
\end{tabular}

O cuidador com o passar do tempo vai se adaptando aos cuidados e aceitando melhor a doença do paciente e o papel de cuidar que exercem (Laham, 2003), ou seja, se conforma com a sua nova vida, acostumando com as tarefas de cuidar. No entanto, estes cuidadores se esquecem do autocuidado, o que leva a uma qualidade de vida ruim, como ilustra nos depoimentos abaixo:

“O cuidado é mais uma obrigação, por ser um membro próximo da família.” (A.J, 57 anos - CI).

"Faz parte da obrigação, sou filha.” (J.R.A., 54 anos - CI).

"Ela cuidou de mim a vida inteira, agora tenho que cuidar dela." (M. J, 50 anos - CI).

"Minha qualidade de vida até que é boa, não posso reclamar." (A.M., 63 anos - CF).

O cuidador passa a se conformar com sua postura de "quieto no seu canto" no convívio familiar, que espera dele uma abnegação servil (Braz, 2008). 
O estudo de Amendola, Oliveira, Alvarenga (2008), indicou que cuidadores familiares de pacientes dependentes estão cuidando de pessoas com alto grau de incapacidade funcional e que a sobrecarga afeta diretamente a Qualidade de Vida (QV) desses familiares. Somando-se a isso, trata-se de uma população carente, com pouca oferta de lazer e cultura, com baixo nível de escolaridade, acometida por doenças crônicas e contam quase que, exclusivamente, com a rede de apoio informal familiar.

Desta forma, acredita-se que há mudanças na QV dos cuidadores, pois além da sobrecarga de atividades, existe mudança nos relacionamentos familiares e no círculo de amizades (Paulo et.al. 2008).

A sobrecarga do cuidador mostra que esta pessoa assume uma responsabilidade além dos seus limites físicos e emocionais, motivo pelo qual necessita ser apoiada, valorizada e reconhecida pelo trabalho que executa (Luzardo, Gorini, Silva, 2006).

\subsubsection{Qualidade de vida por Domínios}

A média dos escores para cada domínio que avaliou a Qualidade de Vida dos CI e dos CF nos aspectos físico, psicológico, das relações sociais e meio ambiente, estão apresentadas nos Gráficos 4 e 5, cujo parâmetro para análise foi baseado no trabalho de Siviero (2003), apud Peres (2013). O referido trabalho considerou os seguintes escores: até $25 \%$ são considerados como insatisfação, entre $25 \%$ a $75 \%$ posição intermediária de satisfação, e acima de $75 \%$ como satisfação. 
Gráfico 4- Avaliação dos domínios: ambiental, social, psicológico e físico dos cuidadores informais.

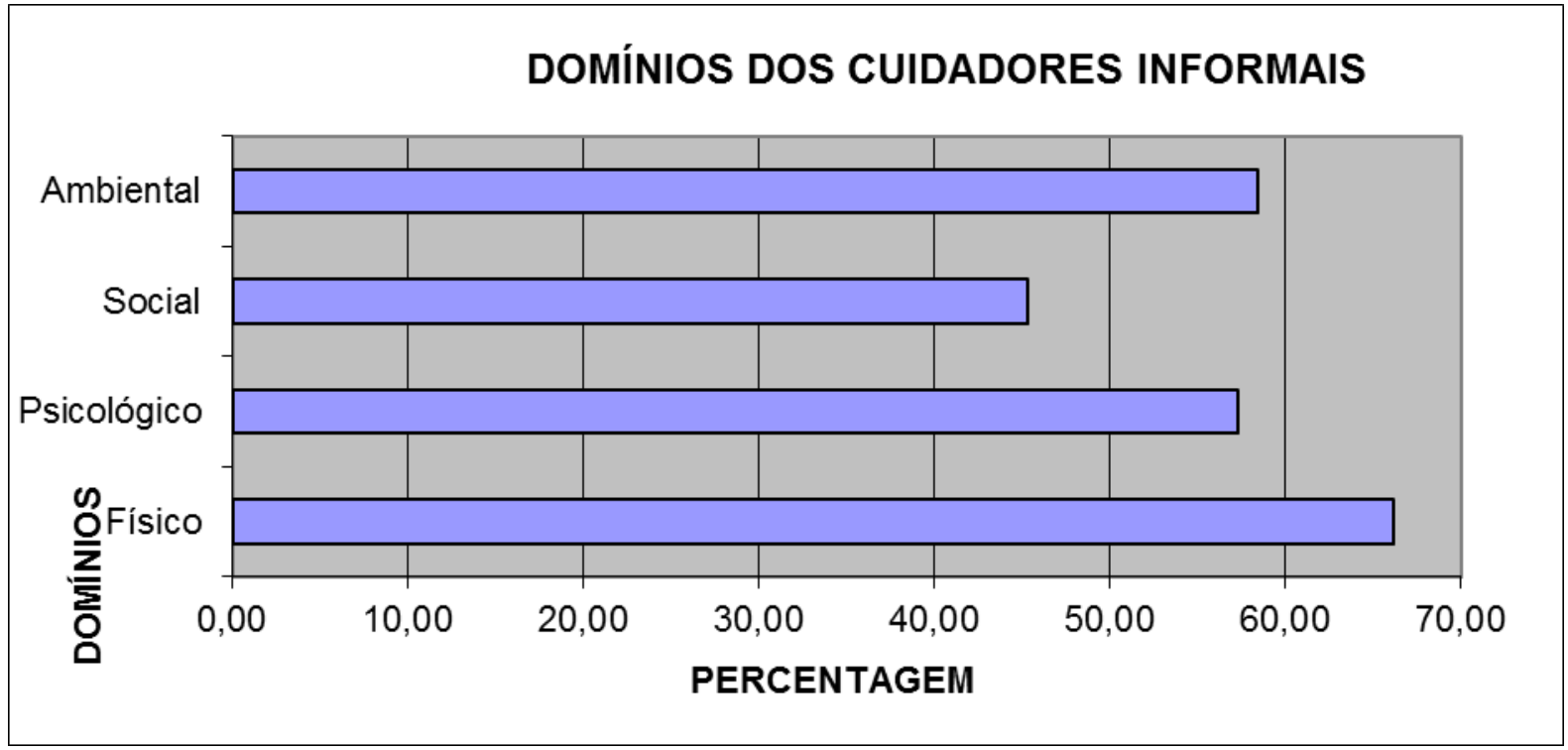

Fonte: Elaborado pela autora

Gráfico 5 - Avaliação dos domínios: ambiental, social, psicológico e físico dos cuidadores formais.

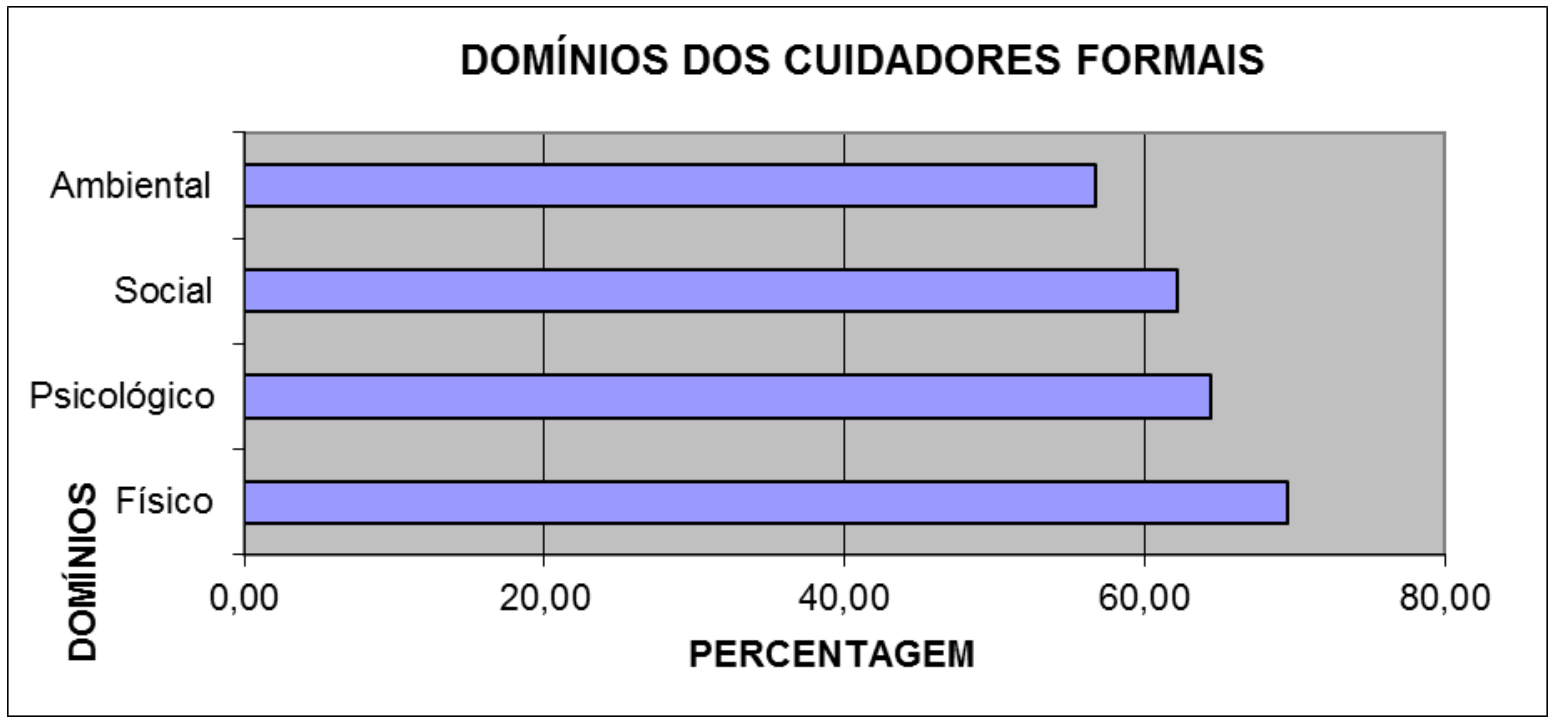

Fonte: Elaborado pela autora

O domínio ambiental dos CI foi de $58,42 \%$ e dos CF foi de $56,67 \%$ (Gráficos 4 e 5). Sendo ambos analisados como grau intermediário de satisfação. 
Quadro 2 - Qualidade de vida no aspecto ambiental dos cuidadores de idosos do Projeto SOL da Unimed de Poços de Caldas, 2012.

\begin{tabular}{|l|l|l|}
\hline $\begin{array}{l}\text { Facetas do Domínio do Meio } \\
\text { Ambiente }\end{array}$ & $\begin{array}{l}\text { Valor do escore } \\
\text { CI }\end{array}$ & $\begin{array}{l}\text { médio } \\
\text { CF }\end{array}$ \\
\hline $\begin{array}{l}\text { Quão seguro (a) você se sente em sua } \\
\text { vida diária? }\end{array}$ & 3,46 & 3,25 \\
\hline $\begin{array}{l}\text { Quão saudável é o seu ambiente } \\
\text { físico (clima, barulho, poluição, }\end{array}$ & 3,75 & 3,65 \\
$\begin{array}{l}\text { atrativos)? } \\
\text { Você tem dinheiro suficiente para }\end{array}$ & 3,08 & 2,70 \\
\hline $\begin{array}{l}\text { satisfazer suas necessidades? } \\
\text { Quão disponíveis para você estão às } \\
\text { informações que precisa no seu dia- } \\
\text { a-dia? }\end{array}$ & 3,67 & 3,90 \\
\hline $\begin{array}{l}\text { Em que medida você tem } \\
\text { oportunidade de atividade de lazer? }\end{array}$ & 2,00 & 2,15 \\
\hline $\begin{array}{l}\text { Quão satisfeito (a) você está com as } \\
\text { condições do local onde mora? }\end{array}$ & 3,96 & 3,35 \\
\hline $\begin{array}{l}\text { Quão satisfeito (a) você está com o } \\
\text { seu acesso aos serviços de saúde? }\end{array}$ & 3,67 & 3,25 \\
\hline $\begin{array}{l}\text { Quão satisfeito (a) você está com o } \\
\text { seu meio de transporte? }\end{array}$ & 3,50 \\
\hline
\end{tabular}

O menor escore encontrado no domínio ambiental foi a faceta “oportunidade de lazer", tendo um escore de 2,00 (40\%) para CI e 2,15 (43\%) para CF, sendo classificado como "ruim" (Quadro 2). Outro fator agravante para o lazer foi a falta de dinheiro para isto.

$\mathrm{Na}$ questão "Você tem dinheiro suficiente para satisfazer suas necessidades?" encontramos um escore de 3,08 $(61,67 \%)$ para os CI, sendo classificado como intermediário e 2,70 (54\%) para os CF, sendo classificado como "ruim" (Quadro 2). 
Os cuidadores profissionais queixam de sua renda. A realidade em Poços de Caldas, em relação ao salário do cuidador, é de $\mathrm{R} \$ 615,00$ a $\mathrm{R} \$ 1.200,00$ por mês, em uma carga horária que varia entre 8 a 10 horas por dia, incluindo sábados.

\footnotetext{
"Sair como? Não tenho dinheiro para nada. Além disso, saio daqui tão cansada que a única coisa que quero é ir para minha casa”. (D.M., 60 anos - CF).
}

Em relação aos cuidadores informais, é justificado ter a satisfação intermediária, porque alguns dos cuidadores pararam de trabalhar para cuidar do idoso, não recebendo nada por isso, o que leva a uma crise econômica. Além disso, o idoso doente dá muito gasto à família, pois a sua única renda, a aposentadoria, não dá para cobrir todas as despesas, como medicamentos, fraldas, alimentação específica, plano de saúde, entre outros. Também culturalmente é a família que provém o idoso na vida diária e em situação de doença ou momentos de crise, tanto no que diz respeito aos aspectos sociais, financeiro, funcional, material, como no afetivo (Watanabe, Derntl, 2005).

A aposentadoria tende a diminuir o rendimento familiar, isso, agregado aos gastos com medicamentos, reduzem-no ainda mais, principalmente pela alta incidência de doenças crônicas entre idosos. A diminuição dos recursos financeiros torna-se uma fonte de estresse, gerando sentimentos negativos que certamente comprometerão a saúde do cuidador e do ser cuidado (Braz, 2008).

O escore de "quão satisfeito com as condições onde mora" foi de 3,96 (79,17\%) para os CI e 3,90 (78\%) para os CF, sendo classificado como "bom", pois todos moram em condições mínimas para uma boa QV. (Quadro 2).

Em relação à questão sobre a satisfação com o meio de transporte, o escore ficou em 3,5 (70\%) para os CI e 3,25 (65\%) para os CF, sendo classificado como intermediário, pois alguns dos cuidadores possuem carro e, os que não possuem, o ônibus passa na porta de suas residências, não 
havendo dificuldades. A única reclamação é em relação ao preço do transporte, que referem ser muito caro (Quadro 2).

Um estudo de Bocchi (2004) aponta que os cuidadores familiares de idosos geralmente têm problemas financeiros, pois na maioria das vezes ou abandonam o emprego ou reduzem a jornada de trabalho. Estima-se que mais de $14 \%$ dos cuidadores informais desistem de seus empregos. Os efeitos sobre os problemas financeiros se dão, mesmo recebendo os benefícios.

“O trabalho diário, somado à carga financeira e ao desgaste físico, leva ao cansaço e às inúmeras incertezas vivenciadas pelo cuidador, gerando angústia, insegurança, culpa e desânimo (Braz, 2008).”

O pior domínio foi o social, tendo resultado de $45,31 \%$ para os CI e 62,19\% para os CF, classificados como "satisfação intermediária". Entretanto, os cuidadores informais estão bem próximos de "insatisfatória" (Gráfico 4 e 5).

Quadro 3- Análise da qualidade de vida no aspecto social dos cuidadores de idosos do Projeto SOL da Unimed de Poços de Caldas, 2012.

\begin{tabular}{|l|l|l|}
\hline $\begin{array}{l}\text { Facetas do Domínio Relações } \\
\text { Sociais }\end{array}$ & $\begin{array}{l}\text { Valor do escore } \\
\text { CI }\end{array}$ & $\begin{array}{l}\text { médio } \\
\text { CF }\end{array}$ \\
\hline $\begin{array}{l}\text { Quão satisfeito (a) você está com } \\
\text { suas relações pessoais? }\end{array}$ & $\mathbf{3 , 7 1}$ & $\mathbf{4 , 0 5}$ \\
\hline $\begin{array}{l}\text { Quão satisfeito (a) você está com } \\
\text { sua vida sexual? }\end{array}$ & $\mathbf{2 , 1 3}$ & $\mathbf{3 , 1 0}$ \\
\hline $\begin{array}{l}\text { Quão satisfeito (a) você está com o } \\
\text { apoio que você recebe de seus } \\
\text { amigos? }\end{array}$ & 3,29 & \\
\hline
\end{tabular}

Talvez isto seja explicado pela falta de tempo que os cuidadores têm para si, pois suas tarefas com o idoso debilitado ocupam quase a totalidade do tempo do dia, não favorecendo uma vida social ativa, principalmente dos cuidadores informais, pois residem com o idoso (100\% dos CI deste estudo). 
Destes cuidadores é exigida habilidade manual, cama limpa, cumprimento dos horários de tomada dos medicamentos, alimentação apropriada e na hora certa, banho de Sol, amor, entre outros cuidados. Esse excesso de atividades pode colocar em risco o ato de cuidar e a saúde do cuidador (Almeida, 2005).

O escore médio da questão sobre as relações pessoais foi de 3,71 (74,17\%) dos CI, sendo classificado como "satisfação intermediária", porém bem próxima de "satisfatória" e 4,05 (81\%) dos CF, classificada como "satisfatória". Alguns cuidadores informais relataram que após a doença perderam o contato com muitos amigos, por dois motivos: primeiro, porque não têm tempo para sair, e segundo porque os amigos quase não vêm visitálos (Quadro 3).

Alguns desses cuidadores relataram que sentem vontade de viajar, mas não têm com quem deixar o idoso. Outros relataram que não conseguem nem ir à missa, que era um costume semanal e muito enraizado em Minas Gerais, perdendo assim, contato com os amigos.

“O homem é um ser social, não consegue sobreviver sozinho. Sua dependência mesmo que física, advém desde os primeiros momentos de vida (Braz, 2008)."

A atividade social é um dos primeiros aspectos a sofrer transformação quando um indivíduo se torna cuidador. O lazer associado a visitas a amigos, idas a igrejas ou até mesmo tarefas rotineiras fora do âmbito doméstico, acabam ficando em um segundo plano (Braz, 2008).

Laham (2003) coloca como a "sensação de prisão", "perda da liberdade", que estando aliada à falta de apoio de outras pessoas para os cuidados, a solidão, o cansaço, tudo isto parece formar uma combinação explosiva, em que os cuidadores não têm lugar para exercerem suas vontades.

Como o olhar da sociedade é voltado para o idoso dependente, a atenção à saúde do cuidador fica esquecida, tanto pelos que os cercam e até por ele próprio (Braz, 2008).

O escore médio da satisfação com o apoio que os cuidadores recebem dos amigos ficou de 3,29 (65,83\%) para os CI e 3,70 (74\%) para os 
$\mathrm{CF}$, estando como "Intermediária", bem próxima de "satisfatória" (Quadro $3)$.

Muitos cuidadores familiares relataram que, quando o ente querido ficou doente, os amigos sumiram. E que, quando recebem visitas, é exclusiva ao doente.

Alguns cuidadores relataram que os parentes quando vêm visitar o idoso, ao invés de ajudar nas tarefas de cuidado ao idoso debilitado, dão mais trabalho ainda. Além da necessidade de recepcioná-los, continuam exercendo os cuidados diários com o idoso, pois os parentes não se oferecem para ajudar.

Verifica-se que não existe uma estrutura familiar capaz de dividir as tarefas do cuidar com o cuidador. A divisão do cuidado possibilitaria uma melhor qualidade de vida para o cuidador com benefícios para o idoso dependente.

Alguns cuidadores formais reclamaram da família do idoso doente, colocando que a família não colaborava com nada nos cuidados ao idoso, como ilustra no depoimento a seguir:

\footnotetext{
"Cuido da idosa o dia todo. Viro ela várias vezes de posição para ver se a escara no trocânter direito fecha. No entanto, à noite, a família deixa ela em cima da escara a noite inteira. Se ela toca o sino para chamar eles, reclamam com ela. Esses dias, quando cheguei na segunda, fiquei sabendo que ninguém tinha dado banho nela no domingo. Assim, o tratamento dela não evolui, pelo contrário, piorou. E a culpa é sempre do cuidador" (J. A. , 45 anos - CF).
}

Assim, Mendes (2005) coloca que, quando um idoso fica dependente de cuidados no domicílio, o cotidiano da família é totalmente alterado em função das atividades colocadas pelo familiar. É introduzida uma nova rotina, desestabilizando relações de intimidade no grupo familiar.

Em relação à questão sexual, que foi o escore mais baixo nesta faceta, tendo um resultado de $2,13(42,50 \%)$ para os CI, sendo classificado como "insatisfatória" e 3,10 (62\%) para os CF classificada como "intermediária" (Quadro 3).

A questão sexual pode ser explicada por várias questões. Uma das cuidadoras familiares é irmã de caridade. Sendo assim, possui o voto de 
castidade. Outros cuidadores são solteiros, não possuindo companheiros, fato esse dificultado pela falta de uma vida social ativa, devido ao grande compromisso com o idoso e à falta de apoio familiar que otimize a vida social. Isso interfere diretamente na vida ativa sexual. Alguns cuidadores cuidam de seu cônjuge, que se encontra debilitado, sendo este um dificultador para a vida sexual.

O estudo de Bocchi (2004) aponta que os conjugês relatam estar vivenciando mudanças radicais impostas pela doença, levando-os a se sentirem insatisfeitos com seus casamentos.

Os cônjuges acabam vivenciando os mesmos problemas do paciente, tais como: mudança no estilo de vida, depressão, frustração, trabalho extra, problemas de comunicação, perda da independência, da confiança e da concentração, sentimentos de inutilidade e de solidão (Bocchi, 2004).

Em relação ao domínio psicológico o resultado foi de 57,29\% para os CI e 64,38\% para os CF, sendo classificados como "satisfação intermediária" (Gráficos 4 e 5).

Quadro 4 - Qualidade de vida no aspecto psicológico dos cuidadores de idosos do Projeto SOL da Unimed Poços de Caldas, 2012.

\begin{tabular}{|c|c|c|}
\hline Facetas do domínio psicológico & $\begin{array}{l}\text { Valor do escore } \\
\text { CI }\end{array}$ & $\begin{array}{l}\text { médio } \\
\text { CF }\end{array}$ \\
\hline O quanto você aproveita a vida? & 2,21 & 2,30 \\
\hline $\begin{array}{l}\text { Em que medida você acha que a sua } \\
\text { vida tem sentido? }\end{array}$ & 3,63 & 4,00 \\
\hline $\begin{array}{l}\text { O quanto você consegue se } \\
\text { concentrar? }\end{array}$ & 2,88 & 3,35 \\
\hline $\begin{array}{l}\text { Você é capaz de aceitar sua } \\
\text { aparência física? }\end{array}$ & 3,54 & 3,55 \\
\hline $\begin{array}{l}\text { Quão satisfeito (a) você está consigo } \\
\text { mesmo? }\end{array}$ & 3,58 & 3,90 \\
\hline $\begin{array}{l}\text { Com que frequência você tem } \\
\text { sentimentos negativos tais como } \\
\text { mau humor, desespero, ansiedade e } \\
\text { depressão? }\end{array}$ & 3,46 & 3,85 \\
\hline
\end{tabular}


A faceta que apresentou menor escore médio no domínio psicológico foi "sentimentos positivos - oportunidade de aproveitar a vida", com um valor de 2,21 (44,17\%) para os CI e 2,30 (46\%) para os CF. A falta de oportunidade de aproveitar a vida pode ser explicada pela falta de tempo para atividades de lazer, pois o cuidador principal fica quase que o tempo integral com o idoso debilitado (Quadro 4).

Quando lidamos com doenças ditas "agudas", o período de necessidade de cuidar é limitado, até que possa ser observada a recuperação da saúde e do ritmo de vida da pessoa. Porém, quando as doenças são crônicas, particularmente as degenerativas, não há previsão de encerramento para a administração dos cuidados, que muitas vezes só crescem (Laham, Silva, 2006).

\footnotetext{
"Sempre quando tenho oportunidades de lazer, como: viajar ou ir em algum aniversário de parente, meu marido faz chantagem emocional comigo, sendo assim, nunca saio." (N.F., 68 anos - CI).
}

Laham, Silva (2006) relataram que os cuidadores não podem contar com um período de "férias", a menos que a família tenha uma organização tal que permita isso, mas esta situação é muito rara. O cuidador estressado corre risco de transferir sua insatisfação para o idoso, chegando, por vezes, a ser agressivo e intolerante. O cansaço é cumulativo e é desejável que a pessoa consiga descansar após curtos espaços de tempo.

O cuidador pode apresentar um alto nível de ansiedade, ocasionado por vários fatores, como sobrecarga pela modificação na estrutura familiar, causada pela inversão de papéis sociais. Além disso, do cuidador é exigido dedicação, responsabilidade, paciência e abnegação e ao mesmo tempo é invadido por sua carga emocional, podendo gerar sentimentos ambivalentes em relação ao idoso, testando seus limites psicológicos e sua postura de enfrentamento perante a vida (Luzardo, Gorini, Silva, 2006).

$\mathrm{Na}$ faceta "O quanto você consegue se concentrar?" ocorreu um escore baixo para os cuidadores informais, sendo de 2,88 (57,50\%) (Quadro 
4). Podendo ser justificado pelo fato dos cuidadores informais ficarem o tempo todo com o idoso, como ilustrado nos depoimentos abaixo:

\footnotetext{
"Mesmo quando minha mãe esta dormindo, escuto ela me gritando. A voz dela pedindo ajuda não sai da minha cabeça" (AL, 56 anos - CI).

"Fico tensa o dia todo. O amor que tenho por ele é muito grande. Se vou ler um livro, ou na padaria, fico pensando nele, no quanto que gostaria que ele voltasse a ser como era antes." (CM, 48 anos - CI).
}

Referente ao domínio físico vale ressaltar que teve o melhor escore médio referente às outras facetas, estando bem próximo da QV "Boa", sendo 66,15\% para os CI e 69,48\% para os CF (Gráficos 4 e 5).

Quadro 5- Qualidade de vida no aspecto físico dos cuidadores de idosos do Projeto SOL da Unimed de Poços de caldas, 2012.

\begin{tabular}{|l|ll|}
\hline Facetas do Domínio Físico & $\begin{array}{l}\text { Valor do escore } \\
\text { CI }\end{array}$ & $\begin{array}{l}\text { médio } \\
\text { CF }\end{array}$ \\
\hline $\begin{array}{l}\text { Em que medida você acha sua dor } \\
\text { (física) impede você de fazer o que } \\
\text { precisa? }\end{array}$ & $\mathbf{3 , 6 3}$ & $\mathbf{4 , 2 0}$ \\
\hline $\begin{array}{l}\text { O quanto você precisa de algum } \\
\text { tratamento médico para levar sua } \\
\text { vida diária? }\end{array}$ & $\mathbf{3 , 5 4}$ & $\mathbf{3 , 8 0}$ \\
\hline $\begin{array}{l}\text { Você tem energia suficiente para o } \\
\text { seu dia-a-dia? }\end{array}$ & $\mathbf{3 , 5 4}$ & $\mathbf{3 , 4 5}$ \\
\hline $\begin{array}{l}\text { Quão bem você é capaz de se } \\
\text { locomover? } \\
\text { Quão satisfeito (a) você está com o } \\
\text { seu sono? }\end{array}$ & $\mathbf{4 , 0 4}$ & $\mathbf{4 , 1 0}$ \\
\hline $\begin{array}{l}\text { Quão satisfeito (a) você está com a } \\
\text { sua capacidade de desempenhar as } \\
\text { suas atividades do seu dia-a-dia? } \\
\text { Quão satisfeito (a) você está com a } \\
\text { sua capacidade para o trabalho? }\end{array}$ & $\mathbf{3 , 7 5}$ & $\mathbf{3 , 4 0}$ \\
\hline
\end{tabular}


O Quadro 5, mostra ainda que o menor escore foi referente ao sono. A maioria dos cuidadores necessita de medicamentos para dormir.

Os cuidadores que prestam os serviços à noite sentem insônia, pois o sono é interrompido várias vezes para prestarem os cuidados necessários.

A insônia é caracterizada como uma diminuição total ou parcial da quantidade ou qualidade do sono, provocando dificuldade de iniciar ou mantê-lo. Dentre suas causas mais comuns estão as perturbações neuropsiquiátricas, como os estados de depressão e ansiedade (Câmara VD, Câmara WS, 2006).

Muitos cuidadores relataram serem hipertensos, necessitando de um tratamento diário para viver. Entretanto, eles apenas tomam as medicações indicadas pelo médico, mas não fazem atividade física, alimentação adequada e atividades de lazer.

Bocchi (2004) aponta os desgastes físicos dos cuidadores, o que reforça nossos resultados no qual o cansaço é apontado pela maioria dos cuidadores, os distúrbios do sono pelo fato de dormirem tarde e terem seus sonos interrompidos para oferecerem cuidados, além do aparecimento de cefaleias, perda de peso e hipertensão.

O cuidador pode comprometer sua integridade física pelo estresse ocasionado pela rotina do cuidar. A falta de condição física para a realização de algumas atividades relacionadas ao cuidar dos idosos dependentes, juntamente com a insegurança de não realizá-las de forma adequada, gera no cuidador dificuldade na sua mobilização, podendo provocar dor (Thober, Creutzberg, Viegas, 2005).

"A rotina diária que determina os afazeres do cuidador exclui a sua vontade ou preferência. O cuidador abre mão da sua vida pela daquele ao qual ele está cuidando" (Thober, Creutzberg, Viegas, 2005).

Como foi visto neste estudo, a QV dos cuidadores informais e formais está comprometida. Além dos desgastes econômicos, sociais e psicológicos está o desgaste físico, que ocorre por vários fatores. Os cuidadores são em sua maioria sedentários, pertencentes à meia idade e senescentes; não fazem alongamentos, atribuem o autocuidado em apenas ir ao médico e fazer exames de rotina. As tarefas do cuidar são desgastantes, 
pois os idosos deste estudo são acamados, pesados e necessitam de cuidados diários e ininterruptos.

No estudo de Gonçalves (2002) foi constatado que $78 \%$ dos cuidadores são sedentários. Ainda quanto às questões manifestadas pelos cuidadores, é importante ser dada atenção às queixas encontradas quanto à coluna vertebral. $89,5 \%$ dos cuidadores referem dores na coluna, e $42,1 \%$ destes apresentando dores na coluna lombar. Durante a prestação de cuidados ao idoso, juntamente com as atividades domésticas, o cuidador em suas tarefas realiza levantamento de cargas pesadas, muitas vezes em condições biomecânicas desfavoráveis e sofre tensionamento da musculatura da coluna por manutenção de posturas incorretas. Além destas sobrecargas, a maior parte dos cuidadores é sedentária e possuem desgastes das estruturas músculo-esqueléticas compatíveis com a idade. Resultam em sobrecarga física, sensorial, sensória motora e mental, acabam levando ao comprometimento da QV do cuidador, e consequentemente, do idoso.

O mesmo autor afirma ainda que a saúde e qualidade de vida dos idosos estão diretamente ligadas ao estado físico e psicológico dos seus cuidadores. Quando o cuidador apresenta problemas quanto a sua saúde, o fornecimento adequado de cuidados ficará comprometido, não conseguindo atender o idoso em todas as suas necessidades (Gonçalves, 2002).

No estudo de Fernandes, Garcia (2009), foram encontrados as seguintes sintomatologias mais frequentes dos cuidadores de idosos: dores no corpo, alterações no funcionamento do intestino, problemas cardiovasculares, dislipidemia, gripe frequente, hérnia de disco, osteoporose, problemas hepáticos, artrose e asma.

É dever do fisioterapeuta melhorar o condicionamento físico do cuidador, além de orientar sobre posicionamento postural adequado para o cuidador exercer a sua tarefa, sem afetar a sua saúde.

Deste modo, a atuação do fisioterapeuta deve estar voltada para a saúde da população, comprometendo-se com o indivíduo e sua família. Para conseguir prestar um cuidado com qualidade, o fisioterapeuta precisa ir além da boa técnica É preciso estar sensível às necessidades e às 
circunstâncias de vida do idoso fragilizado e sua família (Valença, Silva, 2011).

Faz-se necessário, portanto, uma reconstrução no conteúdo e na práxis de formação dos fisioterapeutas, para que ampliem sua visão além da doença, buscando conhecer a realidade onde a pessoa idosa fragilizada está inserida - o contexto familiar -, garantindo uma assistência integral e de qualidade (Valença, Silva, 2011).

No estudo de Canonici et.al. (2010) sobre "Efeitos de um programa fisioterapêutico na qualidade de vida e no desgaste mental de cuidadores de idosos com demência de Alzheimer (DA)", os autores observaram que a prática de um programa fisioterapêutico regular e sistematizado contribui em benefícios para uma melhora da percepção de qualidade de vida e para uma atenuação do desgaste mental dos cuidadores de idosos com DA.

A fisioterapia, além de cuidar do paciente idoso, deve ter um olhar aos cuidadores, oferecendo aos mesmos apoio e orientações, pois o ato de cuidar torna-se muito desgastante, não só no estado psíquico, como também no estado físico (Zatt, 2008).

Em suma, a qualidade de vida dos cuidadores seja ele formal ou informal, é semelhante nos vários domínios analisados e está prejudicada por vários aspectos: físicos, emocionais, sociais e financeiros.

É difícil sanar todos os aspectos que envolvem e afetam a qualidade de vida do cuidador, porém, melhorando um dos aspectos, no caso o físico, que é o foco principal do fisioterapeuta, outros em decorrência podem ser melhorados.

Vale ressaltar que, com o crescente aumento de idosos, mais e mais cuidadores serão necessários e que estes sejam vistos com um olhar especial de todos os profissionais de saúde e que na organização e implantação de serviços haja sempre uma visão com atuação multidisciplinar de prevenção e reabilitação voltados a este público. 


\section{CONCLUSÃO}

A pesquisa realizada com 44 cuidadores de idosos restritos ao leito, sendo 24 cuidadores informais e 20 cuidadores formais, permitiu as seguintes conclusões.

Para melhor entender a dinâmica da qualidade de vida dos cuidadores, foi importante conhecer perfil dos idosos restritos ao leito (foco do cuidado), que revelou:

- a idade variou de 60 a 105 anos, sendo a média de 82 anos, caracterizando uma população de idosos velhos. A maior incidência foi na faixa etária de 80 anos ou mais $(61,4 \%)$;

- houve predominância do gênero feminino $(65,9 \%)$, sendo a maioria viúvas $(54,5 \%)$

- a maioria possui doenças crônico-degenerativo, sendo o diagnóstico mais frequente o Mal de Alzheimer (38,6\%) e Acidente Vascular Encefálico $(34,1 \%)$;

- o peso médio foi de $65,7 \mathrm{~kg}$, sendo $79,0 \mathrm{~kg}$ para os homens e $58,9 \mathrm{~kg}$ para as mulheres.

Quanto ao perfil dos cuidadores temos:

- A maioria $(93,2 \%)$ pertence ao sexo feminino, sendo $91,8 \% \mathrm{CI}$ e $95 \% \mathrm{CF}$;

- A idade média dos CI foi de 57 anos, metade pertencentes à meia idade e a outra metade pertencente à chamada $3^{\circ}$ Idade. Os CF tinham idade média de 48 anos (quase 10 anos menos que os $\mathrm{CI}$ ), com um maior contingente na chamada "meia idade" com um total de 90\%;

- Possuem baixo grau de escolaridade, dos CI $50 \%$ possuem o $1^{\circ}$ grau, $41,6 \%$ o $2^{\circ}$ grau e $8,3 \%$ o $3^{\circ}$ grau, e dos CF $60 \%$ possuem o $1^{\circ} \mathrm{Grau}, 35 \%$ o $2^{\circ}$ Grau e apenas $5 \%$ o $3^{\circ} \mathrm{Grau}$;

- A maioria dos cuidadores são casados, sendo 54,1\% dos CI e 60,0 dos CF; 
- Em relação aos CI encontramos: $25 \%$ cônjuges, 58,3\% filhos, 8,3\% netos e $8,3 \%$ irmãos;

- A forma mais comum de ter se tornado cuidador foi o auto aprendizado e, com frequência, é aquela empregada doméstica de confiança, que, quando o idoso ficou doente, "ganhou" as funções de cuidador.

A partir da análise e aplicação de testes estatísticos sobre a QV dos cuidadores, considerando os quatro domínios: físico, psicológico, social e ambiental, conclui-se que os cuidadores, tanto formais quanto informais, analisam sua qualidade de vida após a atividade de cuidar, como intermediária, não tendo diferença significativa entre os dois grupos estudados, porém observamos:

- grande sobrecarga física para os cuidadores, principalmente para aqueles que fazem a transferência do paciente. Grande parte apresenta cifose, ombros e pescoço protusos, sendo que esta postura pode ser explicada por dor e/ou postura do depressivo;

- os cuidadores não têm uma musculatura preparada para fazer a transferência deste idoso várias vezes por dia, ainda mais se considerarmos o peso do idoso, e, com isso, referem-se a dores na coluna e no corpo;

- a automedicação é frequente e ocorre por meio de analgésicos e antiinflamatórios;

- não praticam qualquer tipo de atividade física e não fazem alongamentos com frequência;

- não têm tempo para o autocuidado e, os poucos que "se cuidam", o ato se resume em ir ao médico ou em realizar exames de rotina;

- com o passar do tempo, acabam se conformando com a sua nova vida, acostumando-se com as tarefas de cuidar.

A QV referida, portanto, apresentam-se aquém do desejado, sendo que os piores escores foram encontrados nos domínios psicológico e social, explicado pela falta de oportunidade em "aproveitar a vida", "irem à missa", “viajar”, entre outros, além do cansaço. 
Portanto a QV dos cuidadores seja ele formal ou informal, são semelhantes no vários domínios analisados e está prejudicada por vários aspectos. A prática de um programa fisioterápico regular e sistematizado pode contribuir para uma melhora da percepção de QV e para atenuação do desgaste mental dos cuidadores. 


\section{CONSIDERAÇÕES FINAIS}

O processo de envelhecimento populacional e a alteração na pirâmide epidemiológica vivenciada pelo país nas ultimas décadas trouxe novas preocupações e pesquisas voltadas para o idoso e seus cuidadores.

Os idosos normalmente sofrem de doenças crônicas e degenerativas e, na maioria das vezes, necessitam de um cuidador para fazer suas atividades de vida diária e de vida instrumental.

Como vimos, os cuidadores principais normalmente pertencem ao sexo feminino, cujo papel é visto como natural, uma vez que está inserido socialmente no papel de mãe, constituindo mais um papel assumido dentro da esfera doméstica.

Quando um idoso fica dependente, todo o sistema familiar é atingido. Saber quem é o cuidador principal, como e por que ele surge no sistema familiar, são dados importantes e carentes de investigação.

Idosos mais dependentes fisicamente acabam exigindo mais de seus cuidadores, o que aumenta os desafios e dificuldades no processo de cuidar. A falta de exercícios com os idosos pode, consequentemente, aumentar a sobrecarga dos cuidados, pois este fica com perda da força muscular, não conseguindo ajudar o cuidador na transferência e nem na troca de fraldas. Igualmente, apresentam atrofia muscular e se tornam mais rígidos e, com isto, ficam com menos flexibilidade e se tornam mais pesados.

Os idosos acamados necessitam de cuidados diários e ininterruptos, comprometendo a qualidade de vida do cuidador, que fica com o tempo restrito para realizar o autocuidado e suas atividades sociais. Além disso, os cuidados são desde os mais simples até os mais complexos e muitos cuidadores não estão habilitados para executarem tais tarefas. São necessários cursos profissionalizantes e de qualificação, para que possam executar o cuidado de forma apropriada, sem prejudicar sua saúde e a do ser cuidado.

Entre as consequências da tarefa de cuidar do idoso, é frequente os cuidadores apresentarem limitações na vida profissional, desde a redução da jornada de trabalho até o seu abandono, levando à uma crise econômica na 
família. Observamos que muitos cuidadores apresentam falta de tempo para se cuidar, falta de rodízio na família, têm vontade de ir passear, caminhar ou ir à missa ir à missa. Por consequência, perdem amigos, entram em solidão, entre outros conflitos.

Podemos deduzir que, com o passar do tempo, o cuidador vai se adaptando a sua vida e ao seu papel em relação às tarefas de cuidar, e que, mesmo enfrentando dificuldades e momentos conturbados nesse processo, tenta se adaptar. No entanto, verificou-se que a QV dos cuidadores foi alterada após cuidar do idoso acamado, tendo dores na coluna e sendo negligentes com sua própria saúde. Como ele não realiza o autocuidado, na maioria das vezes, muitos daqueles que tinham uma vida profissional estruturada não conseguem conciliar isso com a sua nova tarefa, desvinculando-se da vida pessoal para dedicar-se integralmente ao paciente.

Cuidar de um idoso nem sempre é um fardo, mas também pode acarretar ônus, pelo fato do cuidador, em especial o informal, estar cuidando de uma pessoa querida. Esses cuidadores, mais que outros, necessitam de atividades de lazer, rodízio da família para o cuidado com o idoso doente, ingressar novamente à sociedade, para não se tornarem adultos doentes de amanhã.

Assim, o modelo de Assistência Domiciliar em que um membro da família é o cuidador principal exige dos profissionais de saúde uma atuação mais efetiva e dinâmica, principalmente no que se refere à orientação, supervisão do cuidado e tomada de decisões na prevenção de desgastes.

Sendo assim, programas devem ser desenvolvidos com objetivo de promover, implantar, implementar e avaliar a sua eficiência na capacitação de cuidadores, sejam eles formais ou informais, em decorrência do crescente fenômeno do envelhecimento e das complicações advindas deste processo.

São necessários, portanto, novos estudos, visando a ampliação do conhecimento sobre os cuidadores, especialmente aqueles voltados às intervenções que contribuam para a melhoria da qualidade de vida desses indivíduos, constituindo modelos para reprodução prática.

Conhecer a QV dos cuidadores e os fatores que a influenciam é imprescindível para planejar ações integrais em saúde que contemplem 
soluções para minimizar os efeitos danosos da sobrecarga referente ao ato do cuidar.

Não é uma tarefa simples cuidar de um idoso, mas se o cuidador tiver orientações de como deve cuidar do paciente, se for acompanhado por uma equipe multidisciplinar e tiver tempo para o autocuidado, o cuidar pode se tornar uma tarefa menos desgastante e até mesmo prazerosa.

As atividades de cuidar de um idoso acamado levam à desgastes físicos, que, se bem orientadas, podem ser amenizados. Porém, a falta de informação e de pesquisas voltadas aos benefícios da fisioterapia domiciliar em determinados grupos, dificulta uma ação eficiente na ampliação e promoção desse tipo de atendimento.

O papel fundamental da fisioterapia no restabelecimento dos idosos acamados em seus domicílios e de seus cuidadores está em focar não somente a saúde do idoso, mas também de seu cuidador.

Assim, o fisioterapeuta necessita trabalhar mais próximo da família do idoso, principalmente do cuidador, com o objetivo de promover o seu bom condicionamento físico. Consequentemente, terão menos dificuldades em desenvolver a atividade de cuidar, que exige do cuidador força e flexibilidade.

O cuidador bem orientado, saudável e também assistido, garantirá a realização adequada dos cuidados com o idoso, melhorando a sua qualidade de vida e do ser cuidado. 


\section{REFERÊNCIAS}

Almeida TL. Características dos cuidadores de idosos dependentes no contexto da saúde da Família [dissertação]. Ribeirão Preto, SP:

Universidade de São Paulo - USP; 2005.

Almeida TT, Jabur NM. Mitos e verdades sobre flexibilidade: reflexões sobre o treinamento de flexibilidade na saúde dos seres humanos.

Motricidade, Ribeirão Preto - SP. 2007; 3(1): 337-344.

Amendola F, Oliveira MAC, Alvarenga MRM. Qualidade de Vida dos cuidadores de pacientes dependentes no Programa de Saúde da Família. Texto Contexto Enfermagem, Florianópolis - SC. 2008; 17(2): 266-272.

Aveiro MC, Aciole GG, Driusso P, Oishi J. Perspectivas da Participação do fisioterapeuta no Programa Saúde da Família na Atenção à Saúde do idoso. Ciência e Saúde Coletiva. 2011; 16(1):1467- 1478.

Born TA. Formação de cuidadores: acompanhamento e avaliação. In: Seminário Velhice Fragilizada, São Paulo: SESCSP, 2006; [Acesso em: 11 jan 2013]. Disponível em:

<http://www.sescsp.org.br/sesc/images/upload/conferencias/366.rtf>.

Boillat ME, Gee D, Bellavance F. Ethical conflits in home care: patient autonomy and physician advocacy. Canadian Family. Physician. 1997; v. 43: p.2136-42 apud Laham CF. Percepção de perdas e ganhos subjetivos entre cuidadores de pacientes atendidos em um programa de assistência domiciliar [dissertação]. São Paulo (SP): Faculdade de Medicina, Universidade de São Paulo; 2003.

Bocchi SCM. Vivenciando a sobrecarga ao vir-a-ser um cuidador familiar de pessoa com Acidente Vascular Encefálico: uma análise do conhecimento. Revista Latino Americano de Enfermagem. 2004; 12(1): 115-121.

Boff L. Saber Cuidar: Ética do Humano - Compaixão pela Terra. $3^{\text {a }}$ edição. Petrópolis: Editora Vozes, 1999.

Braz E. Entre o visível e o Invisível - as representações sociais no cotidiano do senescente cuidador de idosos dependentes. [tese] São Paulo - SP. Escola de Enfermagem da Universidade de São Paulo, 2008.

Braz E, Seganfredo KU, Ciosak SI. O Paradigma da Terceira Idade. Cascavel: Coluna do Saber, 2006.

Braga JL, Alvarenga RMP, Mores JBM. Acidente Vascular Cerebral. Revista Brasileira Médica. 2003; 60(3): 88-94.

Berquó E. Algumas considerações demográficas sobre o envelhecimento da 
população no Brasil. Trabalho apresentado no Seminário Internacional sobre o envelhecimento populacional: uma agenda para o fim do século, Brasília, 1996 apud Braz E. Entre o visível e o Invisível - as representações sociais no cotidiano do senescente cuidador de idosos dependentes. [tese] São Paulo - SP. Escola de Enfermagem da Universidade de São Paulo, 2008.

Bub MBC, Medrano C, Silva CD, Wink S, Liss P, Santos EKA. A noção de cuidado de si mesmo e o conceito de autocuidado na enfermagem. Texto Contexto Enferm, Florianópolis. 2006; 15(Esp.): 152-157.

Castro MR, Figueiredo NMA. O estado da arte sobre cuidado ao idoso: diagnóstico da produção científica em enfermagem. Revista de Saúde Coletiva. Rio de Janeiro - RJ. 2009; 19(3): 743-759.

Caldas CP. Cuidado familiar: a importância da família na atenção à saúde do idoso. In: Saldanha AL, Caldas CP. Saúde do Idoso: a arte de cuidar. Interciência, Rio de Janeiro - RJ. 2004; p:41-47.

Camarano AM. Mulher Idosa: suporte familiar ou agente de mudança? Estudos Avançados. 2003; 17(49): 35-63.

Câmara DC, Câmara WS. Distúrbios no sono. In: Freitas EV, Py L, Neri AL, Cançado FAX, Gozzoni ML, Rocha SM. Tratado de Geriatria e Gerontologia. 2.ed. Rio de Janeiro. Editora Guanabara Koogan, 2006; 2 (32): 348-354.

Canonici AP, Acioli CV, Silva KR, Gonçalves GR. Efeitos de um Programa fisioterapêutico na qualidade de vida e no desgaste mental de cuidadores de idosos com demência de Alzheimer. RBCEH, Passo Fundo - RS. 2010; 7(2): 210-216.

Cano MAT, Ferriani MGC. A organização social da vida familiar através dos tempos. Acta Paul. Enfermagem. 2000; 13(3):25-34.

Cassis SVA, Karnakis T, Moraes TA, Curiati JAE, Quadrante ACR, Magaldi RM. Correlação entre o estresse do cuidador e as características clínicas do paciente portador de demência. Rev Assoc Med Bras. 2007; 53(6): 497-501 apud Pinto MF, Barbosa DA, Ferreti CEL, Souza LF, Fram DS, Belasco AGS. Qualidade de vida de cuidadores de idosos com doença de Alzheimer. Acta Paul Enfermagem. 2009; 22(5): 652-7.

Ceschini M. Organização: Dias, ELF. Wanderley, JS. Mendes, RT. Orientações para cuidadores informais na Assistência Domiciliar. $2^{\text {a }}$ Edição. Campinas-SP. Editora da Unicamp, 2005.

Chaimowicz, F. A saúde dos idosos brasileiros às vésperas do século XXI: problemas, projeções e alternativas. Revista de Saúde Pública. 1997; 31(2): 184-200. 
Ciosak SI, Braz E. Tornar-se cuidador de idosos na senescência. In: XII Conferencia Iberoamericana de Educación en Enfermeria. Montevideo, Uruguay. set, 2013 Resumos pag. 83.

Couto JAB. A trajetória ocupacional de cuidadores formais domiciliares de pessoa idosa: gênero, trabalho, qualificação e cuidado [dissertação]. São Paulo - SP. Universidade de São Paulo - Faculdade de Saúde Pública; 2012.

Diogo MJE, Ceolim MF, Cintra FA. Orientações para idosas que cuidam de idosos no domicílio. Revista da Escola de Enfermagem da USP, São Paulo SP. 2005; 39(1): 97-102.

Duarte YAO, Diogo MJD. Atendimento Domiciliar: Um enfoque Gerontológico. São Paulo: Editora Atheneu; 2000.

Egry EY, Fonseca RMGS. A Família, a visita domiciliária e a enfermagem: Revisitando o processo de trabalho da enfermagem em Saúde Coletiva. Revista da Escola de Enfermagem - USP, São Paulo - SP. 2000; 34(3): 233239.

Fernandes MGM, Golçalves MCR, Costa GMC. O Programa de Atenção à saúde do idoso em João Pessoa - PB - realidades e possibilidades.

Conceitos - João Pessoa. 2002; 5 (7): 146-154.

Fernandes MGM, Garcia TR. Atributos da tensão do cuidador familiar de idosos dependentes. Ver. Esc. Enferm. USP. 2009; 43(4): 818-824.

Ferreira CG, Alexandre TS, Lemos ND. Fatores associados à Qualidade de Vida dos cuidadores de idosos em Assistência Domiciliária. Saúde Soc, São Paulo - SP. 2011; 20(2): 398-409.

Fleck M, Louzada S, Xavier M, Chachamovich E, Vieira G, et. al. V Aplicação da versão em português do instrumento abreviado de avaliação da Qualidade de Vida "WHOQOL - BREF". Revista de Saúde Pública. São Paulo - SP. 2000; 34 (2): 178-83.

Fleck MPA. O Instrumento de avaliação de qualidade de vida da Organização Mundial da Saúde (Whoqol - 100): características e perspectivas. Ciência e Saúde Coletiva. 2000; 5(1): 33-38.

Floriani CA, Scharmm FR. Cuidador do idoso com câncer avançado: um ator vulnerável. Cad. Saúde Pública, Rio de Janeiro - RJ. 2006; 20(4): 986994.

Fries JF. Aging, natural death, and the compression of morbidity. The new England jornal of medicine. 1980. Epub: Bulletin of the World Health Organization. 2002; 80 (3): 245-250. 
Garrido R, Almeida OP. Distúrbios de comportamento em pacientes com demência: impacto na vida do cuidador. Arquivos de Neuropsiquiatria. 1999; 57(2B): 427-434. Grafstrom M, Fratiglioni L, Sandman PO, Winblad B. (1992). Health and social consequences for relatives of demented and non-demented elderly: A population study. Journal Clinical of Epidemiology. 1992; 45(8): 861-870 apud Cruz MN, Hamdan AC. O impacto da doença de Alzheimer no cuidador. Psicologia em estudo, Maringá. 2008; 13(2): 223-229.

Gonçalves LO. Cuidadores primários familiares dos idosos atendidos na clínica Escola de Fisioterapia da Universidade do Vale do Itajaí - Univali. [dissertação]. Universidade Federal de Santa Catarina, Florianópolis - SC; 2002.

Gonçalves LHT, Alvarez AM, Sena ELS, Santana LWS, Vicente FR. Perfil da família cuidadora de idoso doente/fragilizado do contexto sociocultural de Florianópolis, SC. Texto Contexto Enfermagem, Florianópolis - SC. 2006; 15(4): 570-577.

Guedea MTD, Damacena FA, Marcobich PO, Carbajal MMM, Hernández GA, Lizárraga LV, et.al. Necessidades de Apoio Social em Cuidadores de Familiares Idosos Mexicanos. Psicologia \& Sociedade. 2009; 21(2): 242249.

Guimarães NA, Hirata HS, Sugita K. Cuidado e cuidadoras: o trabalho de care no Brasil, França e Japão. Trad. De Philippe Dietman. Sociologia \& Antropologia. 2011; 1(1): 151-180.

Hooyman N, Kiyak HA. Social gerontology - a multidisciplinar perspective. Needham Heights: Allyn and Bacon. The importance of social supports: family, friends, and neighbors; 1996; 4: 282-95 apud Diogo MJE, Ceolim MF, Cintra FA. Orientações para idosas que cuidam de idosos no domicílio. Revista da Escola de Enfermagem da USP, São Paulo - SP. 2005; 39(1): 97102.

Inouye K, Pedrazzani ES, Pavarini SCI, Toyoda CY. Percepção de qualidade de vida do idoso com demência e seu cuidador familiar: avaliação e correlação. Revista latino Americano de Enfermagem. 2009; 17(2): 1-7.

IBGE- Instituto Brasileiro de Geografia e Estatística. Censo populacional de 2010. [Acesso em 01 julho de 2012]. Disponível em: www.ibge.gov.br

Laham CF. Percepção de perdas e ganhos subjetivos entre cuidadores de pacientes atendidos em um programa de assistência domiciliar [dissertação]. São Paulo (SP): Faculdade de Medicina, Universidade de São Paulo; 2003.

Laham CF, Silva LA. O Cuidador. In: Jacob, WF, organizador. Avaliação Global do Idoso. São Paulo: Atheneu, 2006. p.171-180. 
Laurente R, Jorge MHPM, Gotlieb SLD. Perfil epidemiológico da morbimortalidade masculina. Ciência \& Saúde Coletiva. 2005; 10(1): 35-46.

Lemos ND, Gazzola JM, Ramos LR. Cuidando do paciente com Alzheimer: o impacto da doença no cuidador. Saúde e Sociedade. 2006; 15(3): 170-179.

Luzardo AR, Gorini MIPC, Silva APSS. Características de idosos com doença de Alzheimer e seus Cuidadores: uma série de casos em um serviço de neurogeriatria. Texto Contexto Enfermagem, Florianópolis - SC. 2006; 15(4): 587-594.

Martins T, Ribeiro JP, Garrett C. Estudo de Validação do questionário de Validação da sobrecarga para cuidadores informais. Psicologia, Saúde e Doenças. 2003; 4(1):131-148.

Mazza MMPR. O cuidado em família sob o olhar do idoso [tese]. São Paulo - SP. Universidade de São Paulo- Escola de Saúde Pública; 2008.

Mendes PBMT. Organização: Dias ELF; Wanderley JS; Mendes RT. Orientações para cuidadores informais na Assistência Domiciliar. $2^{\mathrm{a}}$ Edição. Campinas-SP. Editora da Unicamp, 2005.

Minayo MC. Qualidade de vida e saúde: um debate necessário. Ciência \& saúde coletiva. 2000; 5(1): 7-18.

Montefusco SRA, Bachion MM, Vera I, Caixeta C, Munari DB. Tensão do papel de cuidador: ocorrência em familiares de pessoas com doenças crônicas hospitalizadas. Ciências Cuid. Saúde. 2011; 10(4):828-835.

Mourão M. O livro dos Velhos e a Ciência de envelhecer depois dos 60 anos. Editora Civilização Brasileira, 1945.

Nasri F. O envelhecimento populacional no Brasil. Einstein. 2008; 6 (1): 5456.

Naciones Unidas. Comisión Económica para America Latina y el Caribe (CELADE). Boletim Demográfico da América Latina e do Caribe: envejecimento de la población 1950-2050. 2003.

OPS 2003. Situación de la salud en las Américas. Indicadores e dados básicos. (OPS/AIS/03.01) apud Laurente R, Jorge MHPM, Gotlieb SLD. Perfil epidemiológico da morbi-mortalidade masculina. Ciência \& Saúde Coletiva. 2005; 10(1): 35-46.

Oliveira SL. Tratado de Metodologia Científica. $2^{\circ}$ Edição, 2000, São Paulo - SP.

Omran AR. The epidemiologic transition: A Theory of the epidemiology of population change. The Milbank Memorial fund quarterly. 1971; 49 (4): 
509-538.

OMS - Organização Mundial da Saúde. The WHOQOL Group. The World Health Organization Quality of Life Assessment: Position paper from the World Health Organization. Soc Sci Med. 1995; 10(41): 1403-1409.

Paula JA, Roque FP, Araújo FS. Qualidade de vida em cuidadores de idosos portadores de demência de Alzheimer. Jornal Brasileiro de Psiquiatria. 2008; 57(4): 283-287.

Paulo MG, Teixeira AR, Jotz GP, Barba MC, Bergmann RS. Avaliação da Qualidade de Vida de Cuidadores de Idosos Portadores de Deficiência Auditiva: Influência do Uso de Próteses Auditivas. Arquivo Int. Otorrinolaringol, São Paulo-SP. 2008; 12(1):28-36.

Párraga Diaz M. Quién cuida a los cuidadores? Enfermeria global. Murcia, Espanha. N.6 mayo, 2005.

Perlini NMOG, Faro ACM. Cuidar de Pessoa Incapacitada por Acidente Vascular Cerebral no Domicílio: o fazer do Cuidador Familiar. Revista da Escola de Enfermagem da USP, São Paulo - SP. 2005; 39(2):154-163.

Pimenta GMF, Costa MASMC, Gonçalves LHT, Alvarez AM. Perfil do cuidador de idoso fragilizado em convívio doméstico da grande região do Porto, Portugal. Revista da Escola de Enfermagem - USP. São Paulo. 2009; 43(3): 609-614.

Pinto MF, Barbosa DA, Ferreti CEL, Souza LF, Fram DS, Belasco AGS. Qualidade de vida de cuidadores de idosos com doença de Alzheimer. Acta Paul Enfermagem. 2009; 22(5): 652-7.

Potter PA, Perry AG. Fundamentos de Enfermagem. Trad. Gomes LT, Duarte LH, Nascimento MIC. Rio de Janeiro - RJ. Editora Elsevier Ltda, 2005.

Prefeitura de Poços de Caldas. Dados da Prefeitura de Poços de Caldas, atualizado em 2011 [acesso em 10 junho 2012]. Disponível em: www.pocosdecaldas.mg.gov.br

Ramos LR, Veras R, Kalache A. A populational aging: a brasilian reality. Revista Saúde Pública. 1987; 21(3): 211-24.

Rodrigues SLA, Watanabe HAW, Derntl AM. A saúde de idosos que cuidam de idosos. Revista Esc. Enfermagem USP, São Paulo - SP. 2006; 40 (4): 493-500.

Rodrigues WC. Metodologia Científica. 2007; 25. [Acesso em 01 jun 2012]. Disponível em: http://www. ebras. bio.

br/autor/aulas/metodologia_cientifica. pdf. 
Salgado CDS. Mulher idosa: a feminização da velhice. Estudo Interdisciplinar Envelhecimento, Porto Alegre. 2002; 4: 7-19

Siqueira MEC. As organizações para idosos em Poços de Caldas: pressupostos e práticas. [dissertação]. Campinas - SP. Faculdade Estadual de Campinas, 2000.

Siviero IMP. Saúde Mental e qualidade de Vida de enfartados [tese]. São Paulo: USP. Escola de Enfermagem de Ribeirão Preto; 2003 apud Peres ICS. Qualidade de vida e a relação com o trabalho: percepção do enfermeiro docente [dissertação]. São João da Boa Vista - SP. Centro Universitário das Faculdades Associadas de Ensino; 2013.

Sociedade Brasileira de Cardiologia, Sociedade Brasileira de Hipertensão, Sociedade Brasileira de Nefrologia. V Diretrizes Brasileiras de Hipertensão Arterial, São Paulo - SP. 2006: 1-50.

Souza LM, Wegner W, Gorini MIPC. Educação em saúde: uma estratégia de cuidado ao cuidador leigo. Revista Latino Americana de Enfermagem. 2007; 15(2): 337-43.

Thober E, Creutzberg M, Viegas K. Nível de dependência de idosos e cuidados no âmbito familiar. Revista Bras. Enferm. 2005; 58(4): 438-443.

Trentini CM, Chachamovich E, Figueiredo M, Hirakata VN, Fleck MPA. A percepção de qualidade de vida do idoso avaliada por si próprio e pelo cuidador. Estudos de Psicologia. 2006; 11(2): 191-197.

Valença TDC, Silva LWS. Fisioterapia no cuidado ao sistema familiar: uma abordagem à pessoa idosa fragilizada. Revista Temática Kairós Gerontologia, São Paulo - SP.2011; 14(3):89-104.

Veras R. Em busca de uma assistência adequada à saúde do idoso: revisão da literatura e aplicação de um instrumento de detecção precoce e de previsibilidade de agravos. Caderno Saúde Pública. Rio de Janeiro - RJ. 2003;19 (3): 705-715.

Veras MMS, Pinto VPT, Oliveira EM, Quinderé PHD. O fisioterapeuta na estratégia Saúde da Família: primeiros passos na construção de um novo modelo de atenção. SANARE (periódico na internet), 2004 apud Avieiro MC, Aciole G no Programa Saúde da Família na Atenção à Saúde do idoso. Ciência e Saúde Coletiva. 2011; 16(1): 1467-1478.

Von Korff M, Gruman J, Schaefer J, Curry SJ, Wagner EH. Collaborative management of chronic illness. Ann Intern Med. 1997; 127:1097-1102 apud Mendes EV. O cuidado das condições crônicas na atenção primária à saúde: o imperativo da consolidação da estratégia da saúde da família. Organização Pan-Americana da saúde - Representação Brasil, Brasília - DF. 2012; 1: 
$512 \mathrm{p}$.

Zatt F. A fisioterapia e a doença de Alzheimer: sob o olhar do cuidador [monografia]. Novo Hamburgo - RS, Centro Universitário Feevale; 2008.

Zarit SH. Interventions with Family caregivers. In: Zarit SH, Knight BG (editors). A guide to psychotherapy and aging effective clinical interventions in a life - stage context, Washington, DC. American Psycological Associantion. 1997; p. 139 -59 apud Pinto MF, Barbosa DA, Ferreti CEL, Souza LF, Fram DS, Belasco AGS. Qualidade de vida de cuidadores de idosos com doença de Alzheimer. Acta Paul Enfermagem. 2009; 22(5): 652-7.

Watanabe HAW, Derntl AM. Cuidadores de idosos: uma experiência em Unidade Básica de Saúde. Projeto CapacIDADE. O mundo da saúde. 2005; 29(4): 639-644. 


\section{APÊNDICE I - PERFIL DOS CUIDADORES}

\section{$\underline{\text { A. Identificação do idoso }}$}

Data:

Nome:

Idade: Sexo: ( )F( )M Peso:

Estado Civil: ( )Solteiro ( )Viúvo ( )Casado

Diagnóstico clínico que determinou a dependência:

\section{B. Identificação do cuidador}

Nome: Idade:

Sexo: ( )F ( )M Estado Civil: ( )Solteiro ( )Viúvo ( )Casado

Escolaridade:

Relação cuidador/paciente:( )Profissional ( )Conjugue ( )Filho(a) ( )Neto(a) ( )vizinho(a) ( )Outros

1.Como aprendeu a cuidar? ( )Sozinho ( )Ajuda profissional ( )Curso ( )Outros

2. Na realização das atividades de cuidado com idoso, sente dores no corpo?

( ) $\operatorname{Sim}($ )Não

\section{Se sim}

2.1 A dor permanece após as atividades do cuidar? ( )Sim ( )Não

2.2 Toma alguma medicação ou realiza algum tratamento terapêutico para a dor?

( ) Sim ( )Não

2.2.1 Se sim, Qual?

3. Você faz transferência do paciente? ( )Sim ( )Não

3.1 Se sim, quantas vezes ao dia? ( )1 a 3 ( ) 4 a 6 ( )6 a 10 ( )mais que 10

3.2 Alguém a ajuda para transferir o paciente? ( )Sim ( )Não

4. Você se cuida? ( ) Sim ( )Não

4.1 Como?

5. Você pratica alguma atividade física? ( ) Sim ( )Não

Se sim,

5.1 Qual atividade?

5.2 E qual a frequência que realiza? ( ) 1vez ( ) 2vezes ( )3vezes ( )mais que 3

6. Você realiza alongamentos antes da atividade de "cuidar"? ( )Sim ( )Não 


\title{
APÊNDICE II - TERMO DE CONSENTIMENTO LIVRE E ESCLARECIDO
}

\author{
TERMO DE CONSENTIMENTO LIVRE E ESCLARECIDO
}

Objetivamos com a pesquisa conhecer como ocorre o cuidado e a qualidade de vida do cuidador do idoso acamado, pois seus resultados podem contribuir para desenvolver programas para orientar e promover uma melhor qualidade de vida do cuidador de idosos no domicílio.

$\mathrm{Eu}$,

depois das orientações recebidas, dou meu consentimento para que seja utilizada minha entrevista, realizada pela Pesquisadora Cynthia de Castro Miranda. Neste trabalho, reconheço que minha participação é de livre e espontânea vontade, sendo assegurado o sigilo de minha identidade.

Sei, ainda, que posso abandonar minha participação a qualquer momento sem que sofra qualquer prejuízo ou penalização.

Assim, estou ciente dos meus direitos abaixo relacionados:

1- Garantia de receber informações gerais sobre o significado, justificativa, objetivos e os procedimentos que serão utilizados na pesquisa, bem como o esclarecimento e orientação sobre qualquer dúvida acerca dos procedimentos, riscos, benefícios e outros aspectos relacionados à pesquisa;

2- Liberdade de retirar o meu consentimento a qualquer momento e/ou deixar de participar deste estudo, sem que isto traga prejuízo ou penalização em minha vida cotidiana e frente a sociedade;

3- Segurança de que não serei identificado(a) e que será mantido sigilo e caráter confidencial das informações relacionadas à minha privacidade;

4- De não haver restrições/induções na vontade do sujeito em participar da pesquisa;

5- Garantia de não haver ônus na participação, porque a entrevista que concederei, será realizada em local, data e horário que me seja adequado. Portanto, estou ciente de que não haverá gastos nem ressarcimento e/ou indenização.

Assim, sendo, declaro Meu Consentimento para que sejam usadas as informações que forneci para esta pesquisa, podendo inclusive, torná-las públicas.

Este termo de consentimento terá duas vias, uma que ficará com o(a) senhor(a) e uma que ficará conosco.

Desse modo, concordo em participar deste estudo.

Assinatura do participante:

Data: / /

Qualquer dúvida entrar em contato com:

Cynthia de Castro Miranda: (35)9874- 4257 e-mail:cynthiacmiranda@usp.br

Escola de Enfermagem da USP - Secretária de pesquisa CEPEEUSP: telefone: (11)3061-7548.

E-mail: edipesq@usp.br

Doutora Suely Itsuko Ciosak - email: siciosak@usp.br 


\section{APÊNDICE III - SOLICITAÇÃO DE AUTORIZAÇÃO INSTITUCIONAL}

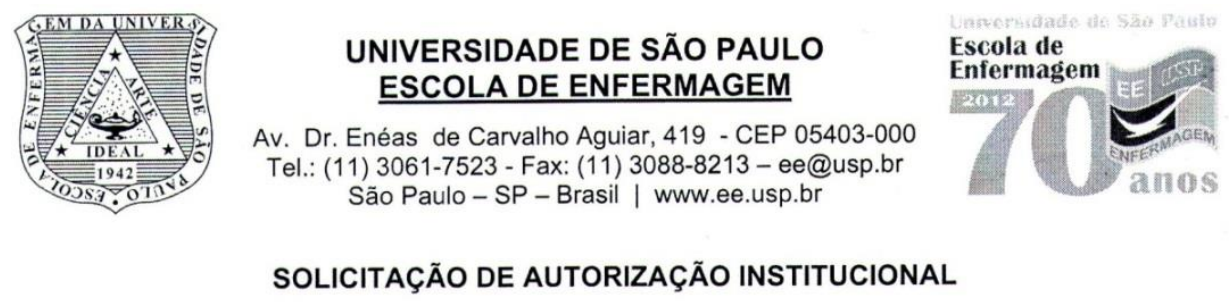

Sao Paulo, 04 de maio de 2012

A Unimed Poços de Caldas

Prezado Diretor Doutor Paulo Januzzi de Carvalho

Solicitamos sua autorização para a realização da pesquisa de mestrado no Programa de Pós Graduação em Enfermagem - PPGE, pela Escola de Enfermagem da Universidade de São Paulo - USP.

A pesquisa abordará o tema Cuidadores de Idosos Restritos ao Leito: estudo da qualidade de vida. A pesquisa está sob a orientação e responsabilidade da Profa. Doutora Suely Itsuko Ciosak.

Esclarecemos que Vossa Senhoria e a Unimed Poços de Caldas não arcará com nenhum custo, que manteremos sigilo sobre todos os dados dos pacientes, cuidadores, profissionais assistentes e que, no final da pesquisa encaminharemos o resultado deste trabalho.

Contamos com seu apoio

Atenciosamente,

Pesquisadoras:

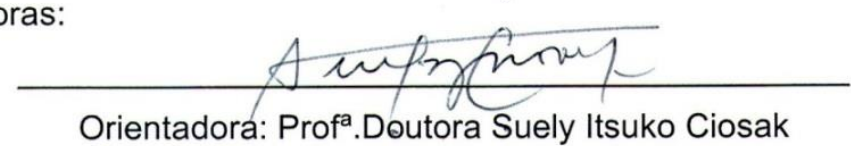

Orientadora: Prof ${ }^{a}$.Doutora Suely Itsuko Ciosak

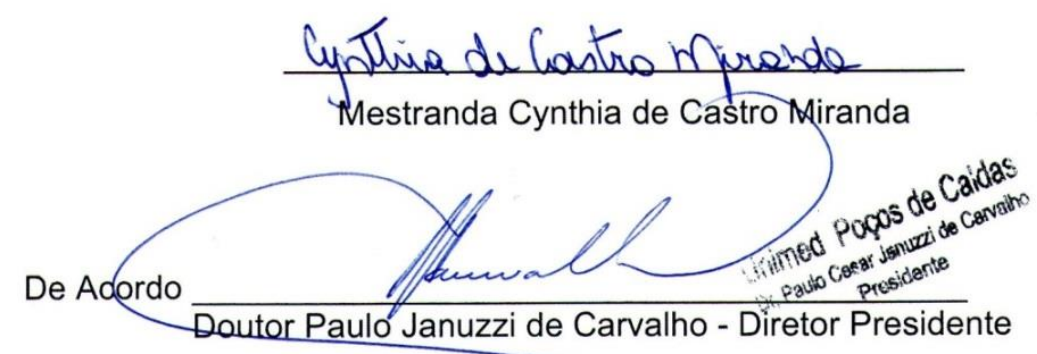

Data: Poços de Caldas 31107112012 


\title{
ANEXO I - WORLD HEALTH ORGANIZATION OF LIFE (WHOQOL - BREF): VERSÃO BRASILEIRA
}

\author{
World Health Organization Quality of Life (WHOQOL - BREF) - \\ Versão Brasileira \\ Instruções
}

Este questionário é sobre como você se sente a respeito de sua qualidade de vida, saúde e outras áreas de sua vida. Por favorresponda a todas as questões. Se você não tem certeza sobre que resposta dar em uma questão, por favor, escolha entre as alternativas a que lhe parece mais apropriada. Esta, muitas vezes, poderá ser sua primeira escolha.

Por favor, tenha em mente seus valores, aspirações, prazeres e preocupações. Nós estamos perguntando o que você acha de sua vida, tomando como como referência as duas últimas semanas. Por exemplo, pensando nas últimas duas semanas, uma questão poderia ser:

\begin{tabular}{|l|c|c|c|c|c|}
\hline & Nada & $\begin{array}{l}\text { Muito } \\
\text { Pouco }\end{array}$ & Médio & Muito & Completamente \\
\hline $\begin{array}{l}\text { Você recebeu dos outros } \\
\text { o apoio que necessita? }\end{array}$ & 1 & 2 & 3 & 4 & 5 \\
\hline
\end{tabular}

recebe

Você deve circular o número que melhor corresponde ao quanto você outros o apoio de que necessita nestas últimas duas semanas.

Por favor, leia cada questão, veja o que você acha e circule no número e lhe parece a melhor resposta.

\begin{tabular}{|l|l|l|l|l|l|}
\hline & $\begin{array}{l}\text { Muito } \\
\text { Ruim }\end{array}$ & Ruim & $\begin{array}{l}\text { Nem ruim } \\
\text { nem boa }\end{array}$ & Boa & $\begin{array}{l}\text { Muito } \\
\text { Boa }\end{array}$ \\
\hline $\begin{array}{l}\text { 1- Como você } \\
\text { avaliaria sua } \\
\text { qualidade de } \\
\text { vida? }\end{array}$ & 1 & 2 & 3 & 4 & 5 \\
\hline & $\begin{array}{l}\text { Muito } \\
\text { Insatisfeito }\end{array}$ & Insatisfeito & $\begin{array}{l}\text { Nem } \\
\text { insatisfeito } \\
\text { nem } \\
\text { satisfeito }\end{array}$ & Satisfeito & $\begin{array}{l}\text { Muito } \\
\text { Satisfeito }\end{array}$ \\
\hline $\begin{array}{l}2-\text { Quão } \\
\text { satisfeito você } \\
\text { esta? }\end{array}$ & 1 & 2 & 3 & 4 & 5 \\
\hline
\end{tabular}

As questões seguintes são sobre o quanto você tem sentido algumas coisas nas últimas duas semanas.

\begin{tabular}{|l|l|l|l|l|l|}
\hline & Nada & Muito & Mais ou & Bastante & Extremamente \\
\hline
\end{tabular}




\begin{tabular}{|l|l|l|l|l|l|}
\hline & & Pouco & Menos & & \\
\hline $\begin{array}{l}3 \text { - Em que medida você } \\
\text { acha que sua dor (física) } \\
\text { impede você de fazer o } \\
\text { que precisa? }\end{array}$ & 1 & 2 & 3 & 4 & 5 \\
\hline $\begin{array}{l}4-\text { O quanto você precisa } \\
\text { de um tratamento médico } \\
\text { para levar sua vida diária? }\end{array}$ & 1 & 2 & 3 & 4 & 5 \\
\hline $\begin{array}{l}\text { 5- O quanto você } \\
\text { aproveita a vida? }\end{array}$ & 1 & 2 & 3 & 4 & 5 \\
\hline $\begin{array}{l}\text { 6- Em que medida você } \\
\text { acha que sua vida tem } \\
\text { sentido? }\end{array}$ & 1 & 2 & 3 & 4 & 5 \\
\hline $\begin{array}{l}\text { 7- O quanto você } \\
\text { consegue se concentrar? }\end{array}$ & 1 & 2 & 3 & 4 & 5 \\
\hline $\begin{array}{l}8-\text { Quão seguro(a) você } \\
\text { se sente em sua vida } \\
\text { diária? }\end{array}$ & 1 & 2 & 3 & 4 & 5 \\
\hline $\begin{array}{l}\text { 9- Quão saudável é seu } \\
\text { ambiente físico (clima, } \\
\text { barulho, poluição, } \\
\text { atrativos)? }\end{array}$ & 2 & 3 & 4 & 5 \\
\hline
\end{tabular}

As questões seguintes perguntam sobre quão completamente você tem sentido ou é capaz de fazer certas coisas nestas últimas duas semanas.

\begin{tabular}{|l|c|c|c|c|c|}
\hline & Nada & $\begin{array}{l}\text { Muito } \\
\text { Pouco }\end{array}$ & Médio & Muito & Completamente \\
\hline $\begin{array}{l}\text { 10- Você tem energia } \\
\text { suficiente para o seu dia-a- } \\
\text { dia? }\end{array}$ & 1 & 2 & 3 & 4 & 5 \\
\hline $\begin{array}{l}\text { 11- Você é capaz de aceitar } \\
\text { sua aparência física? }\end{array}$ & 1 & 2 & 3 & 4 & 5 \\
\hline $\begin{array}{l}12 \quad-\text { Você tem dinheiro } \\
\text { suficiente para satisfazer suas } \\
\text { necessidades? }\end{array}$ & 1 & 2 & 3 & 4 & 5 \\
\hline $\begin{array}{l}\text { 13- Quão disponíveis para } \\
\text { você estão as informações } \\
\text { que precisa no seu dia-a-dia? }\end{array}$ & 1 & 2 & 3 & 4 & 5 \\
\hline $\begin{array}{l}\text { 14- Em que medida você tem } \\
\text { oportunidades de atividade de }\end{array}$ & 1 & 2 & 3 & 4 & 5 \\
\hline
\end{tabular}




\section{lazer?}

As questões seguintes perguntam sobre quão bem ou satisfeito você se sentiu a respeito de vários aspectos de sua vida nas últimas duas semanas.

\begin{tabular}{|c|c|c|c|c|c|}
\hline & $\begin{array}{l}\text { Muito } \\
\text { Ruim }\end{array}$ & Ruim & $\begin{array}{l}\text { Nem ruim } \\
\text { nem bom }\end{array}$ & Bom & $\begin{array}{l}\text { Muito } \\
\text { Bom }\end{array}$ \\
\hline \multirow{2}{*}{$\begin{array}{l}15-\text { Quão bem } \\
\text { você é capaz de } \\
\text { se locomover? }\end{array}$} & 1 & 2 & 3 & 4 & 5 \\
\hline & $\begin{array}{c}\text { Muito } \\
\text { Insatisfeito }\end{array}$ & Insatisfeito & $\begin{array}{c}\text { Nem } \\
\text { insatisfeito } \\
\text { nem } \\
\text { satisfeito }\end{array}$ & Satisfeito & $\begin{array}{c}\text { Muito } \\
\text { Satisfeito }\end{array}$ \\
\hline $\begin{array}{l}16-\quad \text { Quão } \\
\text { satisfeito(a) você } \\
\text { está com o seu } \\
\text { sono? }\end{array}$ & 1 & 2 & 3 & 4 & 5 \\
\hline $\begin{array}{l}\text { 17- Quão } \\
\text { satisfeito(a) você } \\
\text { está com sua } \\
\text { capacidade de } \\
\text { desempenhar as } \\
\text { atividades do seu } \\
\text { dia-a-dia? }\end{array}$ & 1 & 2 & 3 & 4 & 5 \\
\hline $\begin{array}{lr}18- & \text { Quão } \\
\text { satisfeito(a) você } \\
\text { está com sua } \\
\text { capacidade para } \\
\text { o trabalho? }\end{array}$ & 1 & 2 & 3 & 4 & 5 \\
\hline $\begin{array}{l}19-\quad \text { Quão } \\
\text { satisfeito(a) você } \\
\text { está consigo } \\
\text { mesmo? }\end{array}$ & 1 & 2 & 3 & 4 & 5 \\
\hline $\begin{array}{l}20-\text { Quão } \\
\text { satisfeito(a) você } \\
\text { está com suas } \\
\text { relações pessoais } \\
\text { (amigos, } \\
\text { parentes, } \\
\text { conhecidos, } \\
\text { colegas)? }\end{array}$ & 1 & 2 & 3 & 4 & 5 \\
\hline $\begin{array}{lr}21-\quad \text { Quão } \\
\text { satisfeito(a) você } \\
\text { está com sua } \\
\text { vida sexual? }\end{array}$ & 1 & 2 & 3 & 4 & 5 \\
\hline $\begin{array}{l}22-\text { Quão } \\
\text { satisfeito(a) você } \\
\text { está com o apoio } \\
\text { que você recebe } \\
\text { de seus amigos? }\end{array}$ & 1 & 2 & 3 & 4 & 5 \\
\hline 23- Quão & 1 & 2 & 3 & 4 & 5 \\
\hline
\end{tabular}




\begin{tabular}{|c|c|c|c|c|c|}
\hline $\begin{array}{lr}\text { satisfeito(a) } & \text { você } \\
\text { está com as } \\
\text { condições } \\
\text { local onde mora? }\end{array}$ & & & & & \\
\hline $\begin{array}{lr}24- & \text { Quão } \\
\text { satisfeito(a) } & \text { você } \\
\text { está com o } & \text { seu } \\
\text { acesso } & \text { aos } \\
\text { serviços } & \text { de } \\
\text { saúde? } & \\
\end{array}$ & 1 & 2 & 3 & 4 & 5 \\
\hline $\begin{array}{lr}25- & \text { Quão } \\
\text { satisfeito(a) } & \text { você } \\
\text { está com o } & \text { seu } \\
\text { meio } & \text { de } \\
\text { transporte? } & \end{array}$ & 1 & 2 & 3 & 4 & 5 \\
\hline
\end{tabular}

As questões seguintes referem-se a com que frequência você sentiu ou experimentou certas coisas nas últimas duas semanas.

\begin{tabular}{|c|c|c|c|c|c|}
\hline & Nunca & $\begin{array}{l}\text { Algumas } \\
\text { Vezes }\end{array}$ & Frequentemente & $\begin{array}{c}\text { Muito } \\
\text { frequentemente }\end{array}$ & Sempre \\
\hline $\begin{array}{l}\text { 26- Com que } \\
\text { frequência você } \\
\text { tem } \\
\text { sentimentos } \\
\text { negativos tais } \\
\text { como mau } \\
\text { humor, } \\
\text { desespero, } \\
\text { ansiedade, } \\
\text { depressão? }\end{array}$ & 1 & 2 & 3 & 4 & 5 \\
\hline
\end{tabular}

Alguém lhe ajudou a preencher este questionário?

Quanto tempo você levou para preencher este questionário?

\section{Você tem algum comentário sobre o questionário?}




\section{ANEXO II - DOMÍNIOS E FACETAS DO WHOQOL - BREF}

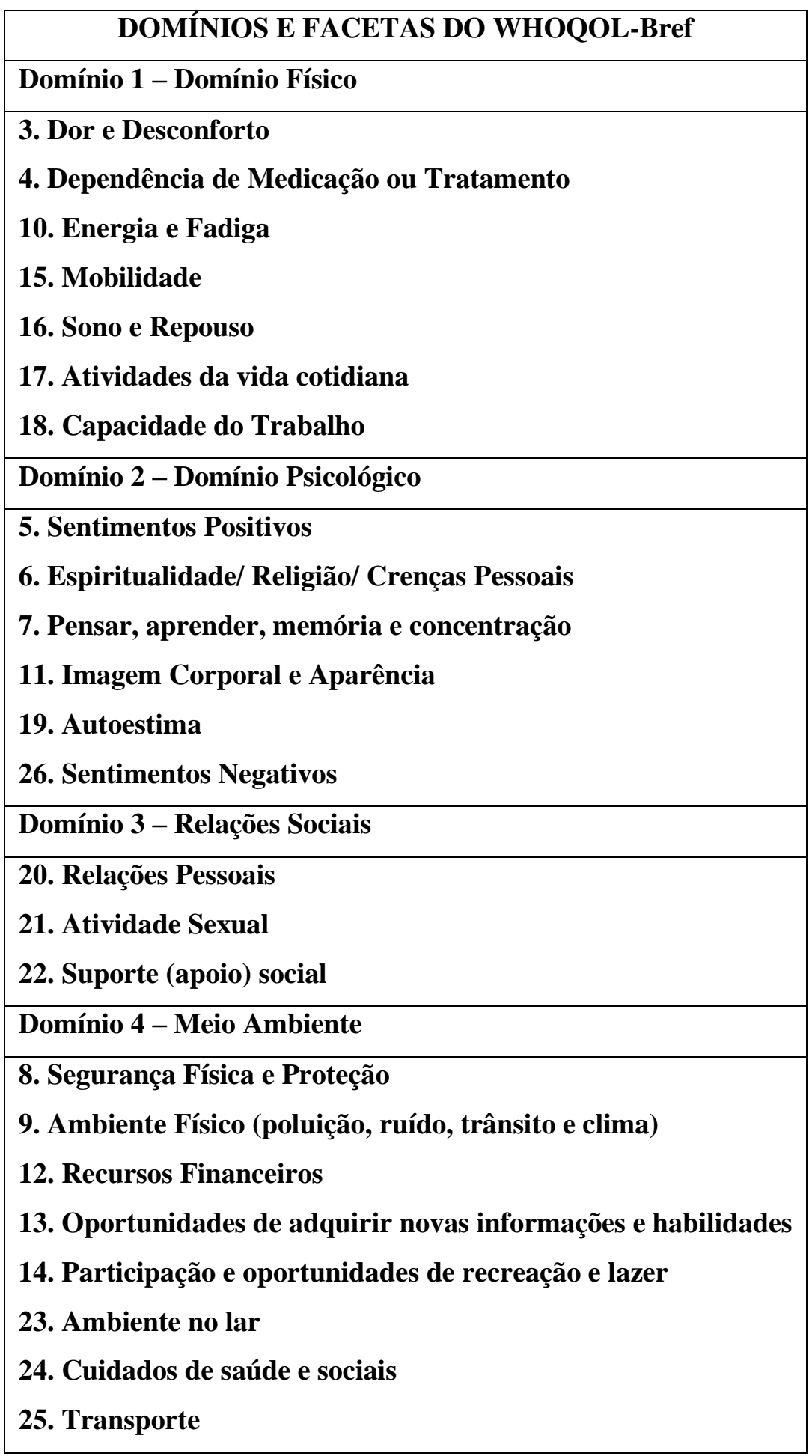

Fonte: (Fleck, Louzado, Xavier, Chachamovich, Vieira, et.al. 2000). 


\section{ANEXO III - CÁlCULO DOS DOMÍNIOS}

\section{PADRONIZADOS DO WHOQOL- BREF}

\section{STEPS FOR CHECKING AND CLEANING DATA AND COMPUTING DOMLIN SCORES FOR THE WHOQOL-BREF}

(prepared by Alison Harper and Mick Power on behalf of the WHOQOL Group)

\begin{tabular}{|c|c|}
\hline Steps & $\begin{array}{c}\text { SPSS syntax for carrying out data checking,cleaning and } \\
\text { computing total scores }\end{array}$ \\
\hline $\begin{array}{l}\text { Check all } \\
26 \text { items } \\
\text { from } \\
\text { assessment } \\
\text { have a } \\
\text { range of } 1-5\end{array}$ & $\begin{array}{l}\text { RECODE Q1 Q2 Q3 Q4 Q5 Q6 Q7 Q8 Q9 Q10 Q11 Q12 Q13 } \\
\text { Q14 Q15 Q16 Q17 Q18 Q19 } 120 \text { Q21 Q22 Q23 Q24 Q25 Q26 } \\
(1=1)(2=2)(3=3)(4=4)(5=5) \text { (ELSE=SYMSIS). } \\
\text { (This recodes all data outside the range } 1-5 \text { to system missing) }\end{array}$ \\
\hline $\begin{array}{l}\text { Reverse } 3 \\
\text { negatively } \\
\text { phrased } \\
\text { items }\end{array}$ & $\begin{array}{l}\text { RECODE Q3 Q4 Q26 }(1=5)(2=4)(3=3)(4=2)(5=1) \\
\text { (This transforms pegatively framed questions to positively framed questions) }\end{array}$ \\
\hline $\begin{array}{l}\text { Compute } \\
\text { domain } \\
\text { scores }\end{array}$ & $\begin{array}{l}\text { COMPUTE PHYS=MEAN.6(Q3,Q4,Q10,Q15,Q16,Q17,Q18)*4. } \\
\text { COMPUTE PSYCH=MEAN.5(Q5,Q6,Q7,Q11,Q19,Q26)*4. } \\
\text { COMPUTE SOCLAL=ME.AN.2(Q20,Q21,Q22)*4. } \\
\text { COMPUTE ENVIR=MEAN.6(Q8,Q9,Q12,Q13,Q14,Q23,Q24,Q25)*4. } \\
\text { (These equations calculate the domain scores. All scores are multiplied by } 4 \text { so as to } \\
\text { be directly comparable with scores derived from the IIHOQOL-100. The ".6" in } \\
\text { "7.AN.6" specifes that } 6 \text { items must be endorsed for the domain score to be } \\
\text { calculated) }\end{array}$ \\
\hline $\begin{array}{l}\text { Transform } \\
\text { scores to } \\
0-100 \text { scale }\end{array}$ & $\begin{array}{l}\text { COMPUTE PHYS }=(\text { PHYS }-4)^{*}(100 / 16) \\
\text { COMPUTE PSYCH }=(\text { PSYCH-4 })^{*}(100 / 16) \\
\text { COMPUTE SOCLAL }=(\text { SOCLAL-4)*(100/16). } \\
\text { COMPUTE ENVIR }=(\text { ENVIR-4)* }(100 / 16)\end{array}$ \\
\hline $\begin{array}{l}\text { Delete cases } \\
\text { with }>20 \% \\
\text { missing } \\
\text { data }\end{array}$ & 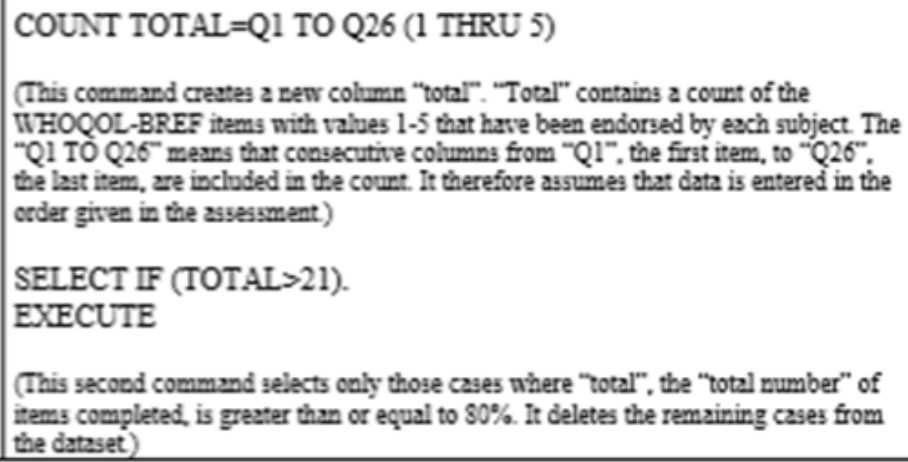 \\
\hline
\end{tabular}




\section{ANEXO IV - APROVAÇÃO DO COMITÊ DE ÉTICA}

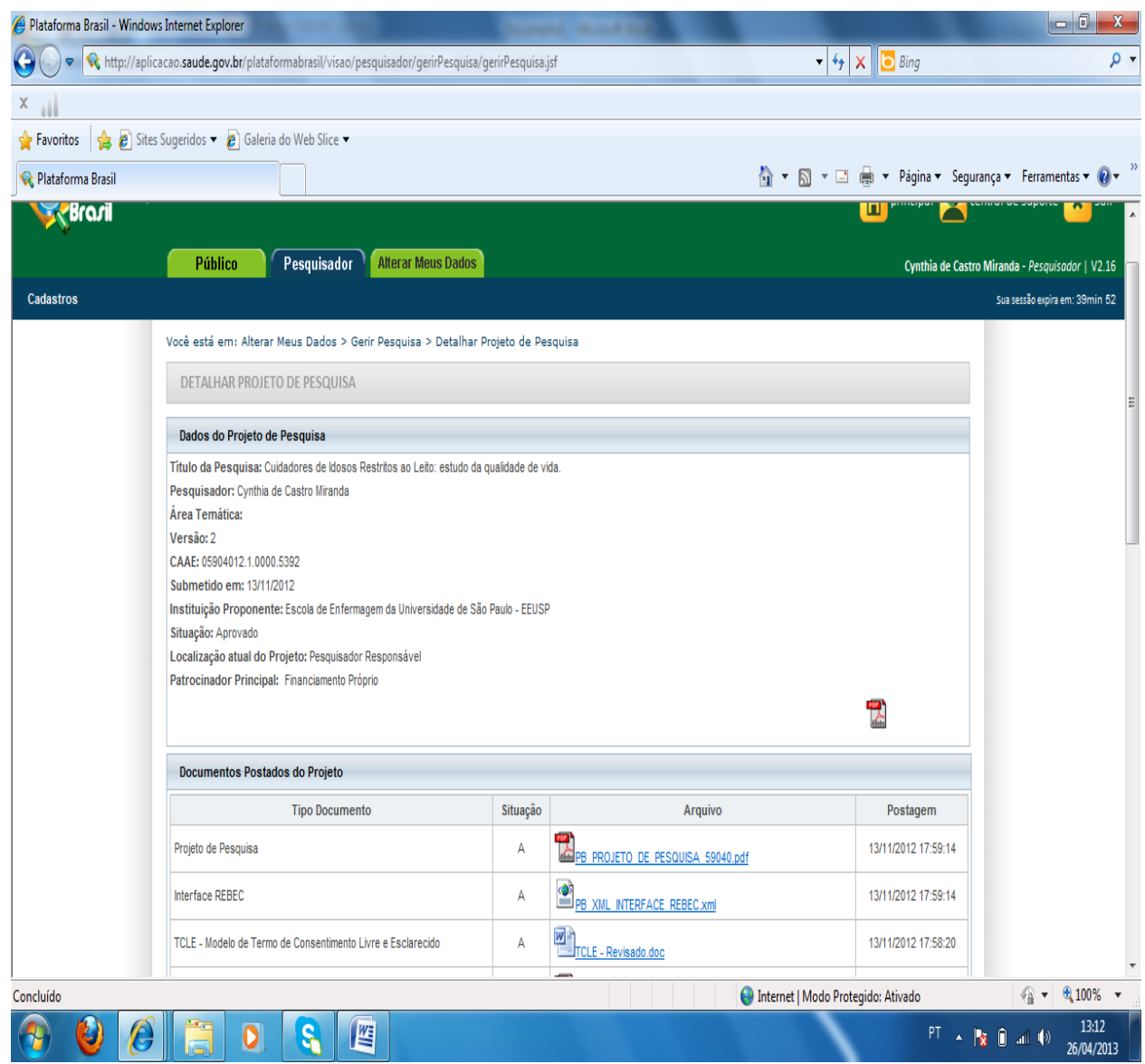

